\title{
Caracterización y fenología de especies de inTERÉs apícola en el departamento Diamante (Entre Ríos, Argentina)
}

\author{
GUILLERMINA A. FAGÚNDEZ¹, PATRICIA D. REINOSO² y PABLO G. ACEÑOLAZA
}

\begin{abstract}
Summary: Characterization and phenology of species with beekeping interest in the Diamante department (Entre Ríos, Argentina). In order to evaluate the bee resources in southwestern region of the province of Entre Rios based on diversity and abundance, spatial and temporal availability of the same, with the purpose to facilitate the planning of beekeeping and compare with the resources exploited by Apis mellifera L., vegetation was surveyed in the area of influence of three apiaries. During the 1999-2001 seasons bee bloom 299 Angiospermae was recorded and coverage was determined in different environments. The botany families with beekeping interest with greater diversity of species were Asteraceae and Fabaceae. The flowering period is extended throughout the year around, with a maximum between mid-October to February. The more relevant in the supply of flowering plant families were Asteraceae, Fabaceae, Apiaceae and Brassicaceae. Tree species make their contribution particularly early in the season, being largely overcome from September forward by herbaceous. The beekeeping resource sector land, it is mainly represented by exotic herbs (e.g. Glycine max, Melilotus albus, Medicago sativa, Lotus corniculatus, Brassica campestris, Ammi and Carduus species) and in the coastal sector and islands by aquatic and marsh native species, either herbaceous (e.g. Sagittaria montevidensis, Polygonum and Eichhornia species) as arboreal (e.g. Salix humboldtiana and Tessaria integrifolia). The wetland species permit to extend the beekeeping period to early autumn.
\end{abstract}

Key words: Flowering phenology, bee resources, southwest region of Entre Ríos.

Resumen: Con el objeto de evaluar los recursos apícolas de la región suroeste de la provincia de Entre Ríos en cuanto a riqueza y abundancia, disponibilidad temporal y espacial de los mismos, se relevó la vegetación en el área de influencia de 3 apiarios. Contar con esta información permitirá favorecer la planificación de la actividad apícola y comparar con los recursos explotados por Apis mellifera. Durante las temporadas apícolas 1999-2001 se registró la floración de 299 Angiospermae y determinó la cobertura en diferentes ambientes. Las familias apícolas con mayor diversidad de especies fueron Asteraceae y Fabaceae. El periodo de floración se extendió durante todo el año, con un máximo entre mediados de octubre a fin de febrero. Las familias botánicas, más relevantes en la oferta de floración fueron Asteraceae, Fabaceae, Apiaceae y Brassicaceae. Las especies arbóreas hacen su aporte principalmente al principio de la temporada, siendo ampliamente superadas desde septiembre en adelante por las herbáceas. El recurso apícola en el sector de tierra firme, se halla representado principalmente por hierbas exóticas (e.g. Glycine max, Melilotus albus, Medicago sativa, Lotus corniculatus, Brassica campestris, especies de Ammi y Carduus) y en el sector costero y de islas por especies nativas acuáticas y palustres, tanto herbáceas (e.g. Sagittaria montevidensis, especies de Polygonum y Eichhornia) como arbóreas (e.g. Salix humboldtiana y Tessaria integrifolia). Las especies del humedal permiten extender el periodo apícola hacia principios de otoño.

Palabras clave: Fenología de floración, recursos apícolas, región suroeste de Entre Ríos.

\footnotetext{
1 Laboratorio de Actuopalinología, CICyTTP-CONICET/ FCyT-UADER. Diamante, Entre Ríos, Argentina. E-mail: guillermina_fagundez@yahoo.com.ar

2 Cátedra Botánica Sistemática, FCA-UNER. Oro Verde, Entre Ríos, Argentina.

${ }^{3}$ Laboratorio de Ecología Vegetal, CICyTTP-CONICET. Diamante, Entre Ríos, Argentina.
} 


\section{INTRODUCCIÓN}

El conocimiento de la riqueza y la distribución espacial y temporal de la vegetación de interés apícola de una región es indispensable para planificar el manejo de las colmenas (Primost et al., 2013). Esta información permite diagramar la trashumancia de las colmenas en función de mayores volúmenes de floración, con la finalidad de optimizar el aprovechamiento de la misma para la obtención de diversos recursos (néctar, polen, propóleos, etc.) o la producción de mieles de determinados orígenes botánicos. Por otro lado, la oferta de floración de una región permite establecer relaciones con los recursos utilizados por la abeja melífera (Apis mellifera L.) e inferir acerca de su comportamiento recolector y preferencias alimenticias.

En Argentina se han desarrollado diversos estudios sobre calendarios apícolas, en las ecoregiones Chaco Húmedo por Cabrera et al. (2013), Salgado (2006) y Salgado et al. (2014) y Chaco Seco por Salgado (2006) y Salgado et al. (2014); en la eco-región Pampa se destacan los realizados por Aramayo et al. (1993), Gurini \& Basilio (1995), Lusardi et al. (2001) y Tellería (1993, 1995); en la eco-región Espinal fueron abordados por Andrada (2003) y Naab et al. (2011). En el Monte de Llanuras y Mesetas dichos estudios involucran los desarrollados por Forcone (2003), Naab \& Tamame (2007) y Tamame (2011); en la eco-región de los Bosques Patagónicos los llevados a cabo por Forcone \& Kutscher (2006), y en la Estepa Patagónica por Forcone \& Muñoz (2009).

La apicultura ocupa un papel importante en la producción pecuaria de Entre Ríos, siendo la segunda provincia productora de miel a nivel nacional (Ferrari et al., 2011), con aproximadamente 620.000 colmenas en producción y 8 millones de toneladas de producción anual (MPPER, 2014). El Departamento Diamante es una de las 17 divisiones político-administrativas que constituyen la provincia de Entre Ríos. Se encuentra ubicado en el extremo suroeste de la misma, teniendo como límite al río Paraná en el oeste (Fig. 1). Posee una superficie total de 253.600 hectáreas y está conformado por dos sectores netamente contrastantes en los aspectos físicos, botánicos y productivos: una parte insular que comprende aproximadamente el $45 \%$ de su territorio, constituida por la región superior del
"Complejo Litoral del Río Paraná" (Aceñolaza et al., 2008; Aceñolaza \& Rodríguez, 2013; Iriondo, 2004), y la parte restante de "tierra firme" (Fig. 1). Posee aproximadamente 11.000 colmenas en producción (MPPER, 2014). En este sentido, la importancia del conocimiento fenológico de las especies de interés apícola se extiende, no solo al mejoramiento de las estrategias de manejo de las colmenas, sino al impacto económico que ésto puede significar.

El presente trabajo tiene como objetivo principal el de evaluar los recursos florísticos disponibles en distintos ambientes de la región suroeste de la provincia de Entre Ríos para ser explotados por Apis mellifera. Para ello, se estudió la abundancia, disponibilidad temporal y espacial de los mismos, a fin de favorecer la planificación de la actividad apícola.

\section{Materiales y Métodos}

\section{Características del área de estudio}

\section{Descripción botánica}

El Departamento Diamante, se halla en un área de transición biogeográfica; según los autores, en él se encuentran representadas las eco-regiones Pampa, Delta e Islas del Paraná y Espinal (Burkart et al., 1999), o también denominadas Pampeana, Delta e Islas del Paraná y del Uruguay, y del Espinal (Morello et al., 2012), o conocidas como provincias Fitogeográficas Pampeana, Paranaense y del Espinal bajo la clasificación dada por Cabrera (1976).

La más representativa, en superficie y por su florística, es la eco-región Pampa. La eco-región Delta e Islas del Paraná, se halla representada por las angostas galerías a lo largo del río Paraná incluyendo sus afluentes, y la del Espinal se manifiesta por medio de intrusiones de especies arbóreas semixerófilas, provenientes de la zona norte, donde son características (Aceñolaza et al., 2004).

Entre los representantes pampeanos, aparecen subfrútices o arbustos de poca altura de los géneros Baccharis, Eupatorium, Vernonia y Heimia (Cabrera, 1976). Los representantes del Delta e Islas del Paraná son especies hidrófilas, las que conforman un estrato arbóreo y otro arbustivo dominantes, acompañados por enredaderas, 


\section{G. Fagúndez et al. - Floración de interés apícola en el SO Entrerriano}
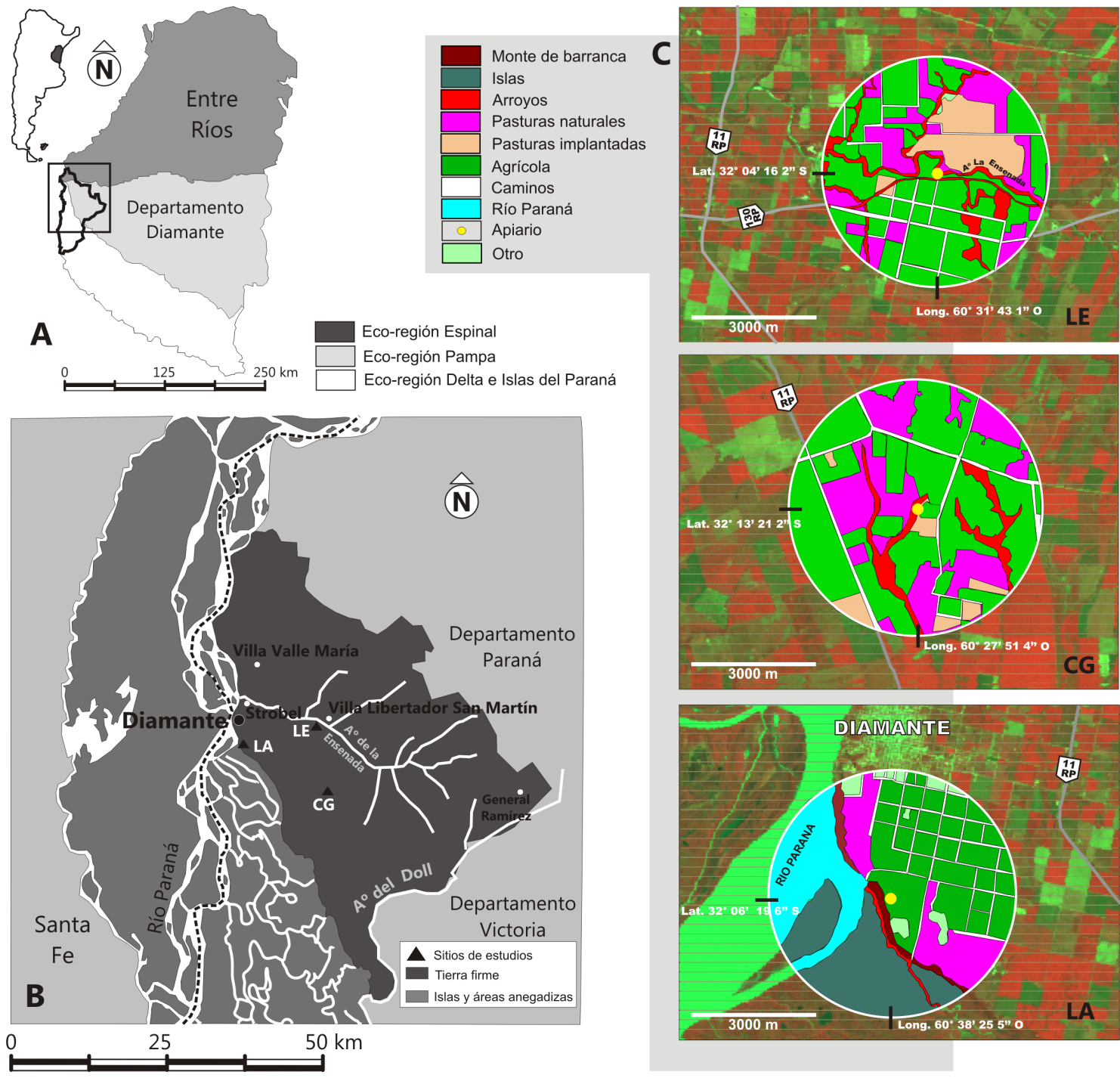

Eco-región Espinal Eco-región Pampa Eco-región Delta e Islas del Paraná

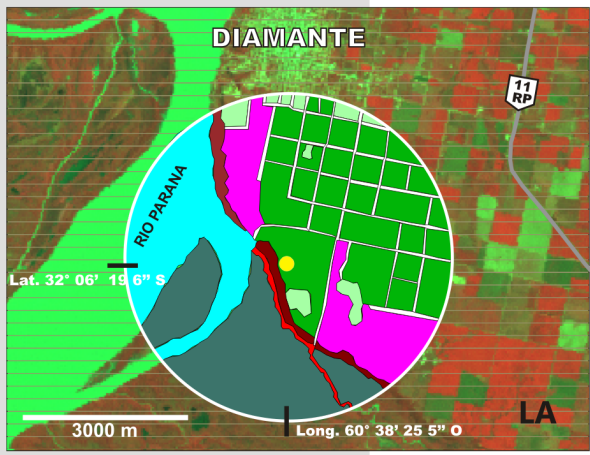

Fig. 1. Localización de los sitios de estudio. A. Eco-regiones presentes en la provincia de Entre Ríos y ubicación del Departamento Diamante. B. Detalles de los sectores de tierra firme y áreas anegadizas presentes en el Dpto. Diamante. Ubicación de los apiarios: LE (La Ensenada), CG (Costa Grande), LA (La Azotea). C. Área de influencia de los apiarios (radio de $3 \mathrm{~km}$ ) categorizada según ambientes.

helechos y plantas epífitas. La composición típica se observa especialmente sobre el río Paraná, mientras que en los arroyos la actividad humana ha modificado o reducido la vegetación natural, apareciendo especies arbustivas y herbáceas altas como Baccharis salicifolia, Panicum prionitis Nees, Cortaderia selloana y subsisten árboles como Salix humboldtiana. Entre los árboles hidrófilos, característicos sobre el río Paraná, son comunes entre otros Zanthoxylum fagara, Myrcianthes cisplatensis, Sideroxylon obtusifolium, Achatocarpus praecox, Phytolacca dioica, S. humboldtiana y Erythrina crista-galli (Muñoz, 1991).

En cuanto al Espinal, se encuentran especies arbóreas semixerófilas, siendo abundantes las del género Prosopis, pero no dominantes, sino que viven entremezcladas con los árboles 
hidrófilos y principalmente en los bordes de los caminos y alambrados. Suelen hallarse $P$. nigra, P. affinis, Celtis ehrenbergiana, Geoffroea decorticans y Parkinsonia aculeata. En el interior del Departamento, los remanentes de vegetación natural se concentran a lo largo de los caminos vecinales, alambrados y vías férreas. En predios agrícolas abandonados cercanos a la costa, aparecen renovales de Acacia caven y $G$. decorticans (Muñoz, 1991).

Sobre la margen oeste del Departamento, lindante con el río Paraná, la distribución de la vegetación sigue el gradiente topográfico (Aceñolaza et al., 2004). Este gradiente está condicionado principalmente por el pulso de inundación, como uno de los determinantes fundamentales del paisaje de humedal; permitiendo diferenciar una única unidad que no sufre inundación: la barranca, de una serie de comunidades que por ubicarse en ambiente de isla sufren periódicamente y en diferente intensidad los efectos de la inundación. En barranca se encuentran una fisonomía de bosque y otra de pastizal/arbustal. El bosque, posee al menos 20 especies de árboles, en el que dominan Rupretchia laxiflora, Myrsine laetevirens, Phytolacca dioica, varias especies de Myrtaceae, Zanthoxylum fagara, Coccoloba argentinensis, Porlieria microphylla y Achatocarpus praecox. El estrato herbáceo es el más rico en especies; en él se encuentran Dicliptera squarrosa, Sida rhombifolia, Teucrium vesicarium, Byttneria urticifolia, Rivina humilis y Melica sarmentosa Nees var. sarmentosa, entre otras. Son frecuentes lianas y enredaderas como Mikania cordifolia (L. f.) Willd., Cayaponia citrullifolia y Ephedra tweediana.

En isla, los albardones de cauce se caracterizan por la presencia de bosques uniespecíficos o de baja diversidad arbórea como los de Salix humboldtiana y de Tessaria integrifolia. En albardones internos, son más frecuentes los bosques de Sapium haematospermum y los de Albizia inundata; también aparece Erythrina crista-galli y ocasionalmente Enterolobium contortisiliquum (Vell.) Morong. En albardones más antiguos y mejor conservados, aparece Nectandra angustifolia (Schrad.) Nees \& Mart., Inga uraguensis Hook. et Arn., S. haematospermum y Croton urucurana Baill. En general en el ambiente de media loma domina la fisonomía herbácea, incluyendo una serie de asociaciones vegetales dominada por Panicum prionitis y varias especies de Polygonum, y más cerca de los cuerpos de agua aparecen Panicum elephantipes Nees ex Trin., Paspalum repens Bergius, Sagittaria montevidensis, Typha latifolia y Schoenoplectus californicus (C.A. Mey.) Soják var. californicus. En este ecotono hacia el ambiente frecuentemente inundado, suele aparecer Solanum glaucophyllum Desf. Por último se encuentran una serie de comunidades acuáticas con plantas de vida libre como Pistia stratiotes L. y diversas especies de Salvinia, Azolla y Eichhornia.

\section{Condiciones climatológicas}

El Departamento Diamante presenta clima subtropical húmedo con estrés hídrico, tormentas y lluvias moderadas (precipitación media anual entre $1250-1000 \mathrm{~mm}$, temperatura media anual $18,4^{\circ}$ ) (Zamboni, 2008). El mes más lluvioso es marzo: $156,8 \mathrm{~mm}$ de promedio y el menos lluvioso es julio: 29,7 mm de promedio. El 69,5\% del total anual se registra desde octubre hasta marzo; esto indica la existencia de un régimen pluviométrico moderadamente monzónico. Presenta frecuentemente sequías temporarias. El verano suele ofrecer numerosos días con temperaturas máximas diarias absolutas superiores a $30^{\circ} \mathrm{C}$, sobre todo en los meses de enero y febrero. El invierno puede llegar a ser riguroso en un escaso lapso de mínimas extremas en los meses de julio, agosto y septiembre (Carta de Suelos de la República Argentina, 1991).

\section{Uso del suelo}

La vegetación natural original del área alta (no sujeta a las inundaciones periódicas del río Paraná) en el departamento Diamante ha sido modificada y reducida por la actividad agrícola, desapareciendo casi totalmente. De la misma, sólo quedan algunos vestigios de selva en galería en los arroyos (Zamboni, 2008). Esto se debe a las pendientes pronunciadas cercanas a las costas de los cursos de agua y en menor medida a la presencia de algunos materiales geológicos formadores de suelos poco aptos para la agricultura (Muñoz, 1991). Diamante es el departamento con mayor desarrollo de la agricultura en la provincia (considerando la superficie de tierra firme) realizándose en menor medida la ganadería, asociada a la actividad tambera principalmente. Los cultivos más destacados tradicionalmente son "soja", "trigo" y "maíz", y en 


\section{G. Fagúndez et al. - Floración de interés apícola en el SO Entrerriano}

menor medida "girasol", "sorgo" y "lino" (Bolsa de Cereales de Entre Ríos, 2016). Entre las forrajeras predominan las praderas de Medicago sativa, Melilotus albus, Lotus corniculatus, Trifolium repens y $T$. pratense, y verdeos de Avena sativa L. En la región de islas, las actividades predominantes son ganadería extensiva y apicultura (Zamboni, 2008; Fagúndez, 2011).

\section{Selección de las áreas de estudio}

Para poder captar la variabilidad espacial del paisaje del suroeste de la Provincia de Entre Ríos, y por consiguiente de su florística, se trabajó con tres apiarios ubicados en áreas representativas de la vegetación.

El apiario La Azotea (LA) se ubica próximo a la localidad de Diamante, hacia el sur y sobre la barranca del Río Paraná; sus coordenadas son 3206'19.6"S y $60^{\circ} 38^{\prime} 25.5^{\prime \prime} \mathrm{O}$. Dicho apiario se sitúa en un bosque nativo de barranca. En el área de influencia $(3 \mathrm{~km}$ de radio) se encuentran predios con vegetación natural destinados al pastoreo de animales, en el que crecen numerosas especies exóticas debido al sobre-pastoreo, ubicados próximos a la barranca del río Paraná. Existen también predios más distantes, destinados a cultivos de cereales y oleaginosas. En los bordes de los caminos se encuentran diversas especies arbóreas y arbustivas nativas generalmente colonizadoras (varias especies de Baccharis y Eupatorium, entre otras), así como también hierbas nativas y exóticas.

El apiario Costa Grande (CG) se encuentra hacia el sur-este del departamento, $2 \mathrm{~km}$ hacia el este de la Ruta Provincial 11; sus coordenadas son $32^{\circ} 13 ' 21.2^{\prime \prime S}$ y $60^{\circ} 27^{\prime} 51.4^{\prime \prime} O$. Dicho apiario se localiza en una zona principalmente agrícola, en la cual también existen lotes con especies forrajeras exóticas implantadas. En sus proximidades se halla un pequeño curso de agua, con vegetación nativa principalmente herbácea; así como un tajamar rodeado de árboles hidrófilos y herbáceas palustres. Los bordes de caminos presentan numerosas especies principalmente herbáceas nativas y exóticas.

El apiario La Ensenada (LE) se localiza hacia el este de la localidad de Diamante, y hacia el norte de la Ruta provincial 130, próximo a la barranca del Arroyo La Ensenada; sus coordenadas son $32^{\circ} 4^{\prime} 16.2^{\prime \prime} \mathrm{S}$ y $60^{\circ} 31^{\prime} 43.1^{\prime \prime} \mathrm{O}$. Dicho apiario se ubica en una zona agrícola-ganadera, asociada a la actividad tambera, por lo cual se encuentran numerosos lotes con praderas artificiales en base a especies forrajeras exóticas. Existen en el área de influencia, lotes con cultivos de cereales y oleaginosas. En el radio de libación de las abejas de este apiario se encuentran especies hidrófilas tanto árboles como arbustos, debido a la cercanía con el Arroyo La Ensenada (Fig. 1).

Las coordenadas de los apiarios se determinaron a través de un GPS [Sistema de posicionamiento Global (Global Positioning System)]. Para su ubicación se utilizó una imagen satelital LANDSAT TM5 (2001) provista por la CONEA (Convenio con CICyTTP-CONICET). Las mismas fueron procesadas con el programa GVSIG versión 1.10. (software libre).

\section{Relevamiento de la vegetación \\ Estimación de abundancia y cobertura}

Las zonas relevadas se encuentran dividas en numerosos predios, cada uno de ellos con usos y manejos del suelo diversos, de manera que la composición botánica se caracteriza por su alta heterogeneidad espacial y temporal. Las áreas de influencia de cada apiario fueron relevadas reconociendo en ellas ambientes, de acuerdo a los usos u ocupaciones, en las siguientes categorías: monte de barranca, costa de río e islas, costa de arroyos, pasturas naturales, pasturas implantadas, agrícola y bordes de caminos.

Para cada sitio se confeccionó un mapa de tipos de cobertura de vegetación realizado por interpretación visual de imágenes satelitales y corroboración a campo (Fig. 1). Se analizó la superficie departamental bajo cultivo extensivo durante los últimos 16 años, a fin de evaluar cambios en el uso del suelo, comprobándose que éstos no fueron significativos. Si bien se registraron fluctuaciones de hasta un $25 \%$ en el área total cultivada durante este periodo, los cultivos implantados y las rotaciones utilizadas en el departamento Diamante no presentaron grandes variaciones (Bolsa de Cereales de Entre Ríos, 2016). Éstas responden principalmente a una importante disminución en la superficie sembrada de maíz (60\%) a favor de la soja (42\%). En cuanto al girasol y lino las superficies sembradas han disminuido paulatinamente hasta desaparecer del 
cultivo en la última campaña agrícola (2014/15) para el primero de ellos y en las tres últimas para el segundo. La "colza" comenzó a cultivarse en el departamento a partir de la campaña agrícola 2012/13 con 3000 ha sembradas, disminuyendo $50 \%$ en cada una de las campañas sucesivas. El área con cultivo de especies forrajeras tanto anuales como perennes se ha mantenido (INDEC-CNA, 2002; Gvozdenovich et al., 2015), fluctuando alrededor de 20.000 hectáreas.

Para estimar la cobertura de cada especie en los ambientes interpretados, se utilizó la escala de abundancia-cobertura de Braun-Blanquet (1979), con las siguientes categorías:

r: Individuos raros o únicos con pequeña cobertura. + : Pocos individuos con pequeña cobertura.

1: Abundantes, pero con un valor de cobertura bajo, o bien pocos individuos pero con un valor de cobertura mayor.

2: Cualquier número de individuos que cubran 5-25\% del área.

3: Cualquier número de individuos que cubran entre 25-50\% del área.

4: Cualquier número de individuos que cubran entre $50-75 \%$ del área.

5: Cualquier número de individuos que cubran > $75 \%$ del área.

\section{Registros fenológicos}

La metodología empleada para el seguimiento de la fenología de la floración fue la propuesta por Anderson \& Hubritch (1940), la cual considera el efecto visual que produce la floración de las distintas especies en el paisaje. Las fenofases relevadas fueron: a- inicio de floración, b- floración plena, c- fin de floración-comienzo de fructificación. Los registros fenológicos fueron realizados en un mínimo de 15 individuos por especie. Se realizaron relevamientos cada 20 días de las especies en floración, en los sitios de muestreo pre-establecidos, durante la temporada apícola 1999-2000 (agostojulio) y con una frecuencia mensual durante la temporada apícola 2000-2001, a fin de corroborar los datos obtenidos durante la primera temporada y evaluar su variabilidad interanual, debido a la inexistencia de trabajos previos en la región. La información obtenida fue complementada con observaciones realizadas mediante recorridos fijos desde la ciudad de Paraná a Diamante, y desde ésta a los sitios de estudio. Se utilizó además la base de datos del herbario de la Facultad de Ciencias Agropecuarias de la Universidad Nacional de Entre Ríos (ERA), para corroborar y ajustar los periodos de floración.

La selección de las especies de interés apícola se hizo en base a observaciones en la zona de estudio y a bibliografía sobre los recursos utilizados por Apis mellifera en Argentina (Andrada et al., 1998, 1999; Basilio, 1996, 1998; Basilio \& Romero, 1996; Costa de Bringas, 1982; Costa de Bringas et al., 1995; Salgado \& Pire 1998, 1999; Tellería, 1988, 1992, 1996a, 1996b).

Especies o familias botánicas con representantes aislados (Cannaceae, Piperaceae, Potamogetonaceae, Punicaceae y Rosaceae) o con escasa importancia apícola (Asclepiadaceae, Cyperaceae y Poaceae) fueron excluidas de los relevamientos fenológicos y de las estimaciones de cobertura. Fueron consideradas solo algunas especies de Poaceae en las que se observó actividad de recolección de polen, como Zea mays, o aquellas en las que se disponía de bibliografía acerca de su utilización, como algunas especies de Paspalum y Cortaderia selloana (Basilio \& Romero, 1996; Díaz Losada et al, 1995; Gurini \& Basilio, 1995; Salgado \& Pire, 1999; Soderstrom \& Calderon, 1971; Youssef et al., 1978).

\section{Determinación taxonómica, hábito y status}

Se recolectaron ejemplares de las especies vegetales en flor para su determinación taxonómica. Las mismas fueron herborizadas e incorporadas al herbario de la Facultad de Ciencias AgropecuariasUNER (ERA). Para la determinación del material se utilizó la siguiente bibliografía: Burkart (1969, 1974, 1979); Burkart et al. (1987); Burkart \& Bacigalupo (2005); Cabrera \& Zardini (1978); Jozami \& Muñoz (1984); Parodi \& Dimitri (1972). La actualización de los taxones, así como la clasificación por hábito y status se hizo en base al Catálogo de Plantas Vasculares de la República Argentina (Zuloaga et al., 1994; Zuloaga \& Morrone, 1996, 1999). Para las especies exóticas se utilizó la base de datos Trópicos del Missouri Botanical Garden.

\section{Cálculo de similitud entre sitios}

La similitud de los sitios de muestreos fue determinado a través del Índice de Jaccard, 


\section{G. Fagúndez et al. - Floración de interés apícola en el SO Entrerriano}

utilizando los datos cualitativos de presencia/ ausencia de las especies relevadas en cada uno de los sitios (McCune \& Grace, 2002) mediante la siguiente fórmula:

$\mathbf{I j}=\mathbf{c} / \mathbf{a}+(\mathbf{b}-\mathbf{c})$

Donde:

a, es el número de especies presentes en el sitio A,

$\mathrm{b}$, es el número de especies presentes en el sitio $\mathrm{B}, \mathrm{y}$

$\mathrm{c}$, es el número de especies que tienen en común A y B.

Este coeficiente valdrá 0 cuando no haya especies compartidas entre ambos sitios, y 1 cuando ambos tengan la misma composición de especies.

\section{Resultados y Discusión}

\section{Relevamiento de la vegetación}

\section{Determinación taxonómica, hábito y status}

El relevamiento de la vegetación realizada en los tres sitios de estudio permitió determinar un total de 357 especies, pertenecientes a 83 familias botánicas. Las familias mejores representadas en riqueza específica fueron Asteraceae (79), Poaceae (34) y Fabaceae (28). En orden decreciente de importancia le siguen Solanaceae (15), Malvaceae y Verbenaceae (12), Apiaceae (10), Polygonaceae (9), Lamiaceae (7), Amaranthaceae y Cyperaceae

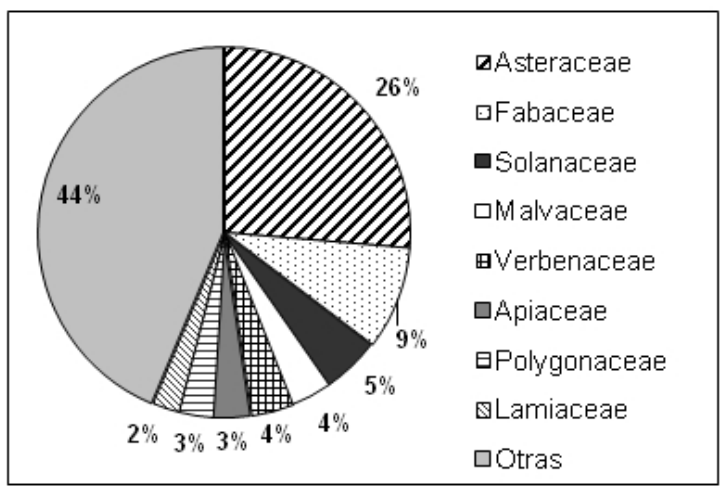

Fig. 2. Distribución porcentual de las familias botánicas de interés apícola mejor representadas en riqueza de especies en los sitios de muestreos relevados.
(6), Euphorbiaceae, Myrtaceae, Rubiaceae y Scrophulariaceae (5), Bignoniaceae, Brassicaceae y Liliaceae (4), Acanthaceae, Boraginaceae, Campanulaceae, Convolvulaceae, Iridaceae, Lythraceae, Moraceae, Onagraceae, Passifloraceae, Pontederiaceae, Rosaceae, Rutaceae y Urticaceae (3), Asclepiadaceae, Caryophyllaceae, Celastraceae, Chenopodiaceae, Commelinaceae, Cucurbitaceae, Ephedraceae, Geraniaceae, Oxalidaceae, Phytolaccaceae, Portulacaceae, Primulaceae, Salicaceae, Turneraceae y Violaceae (2). Las restantes 37 familias estuvieron representadas por solo una (1) especie.

Las especies de interés apícola seleccionadas comprenden un total de 299 , pertenecientes a 76 familias botánicas. Las familias mejor representadas en riqueza específica se muestran en la Figura 2.

En la Figura 3 se presenta la distribución porcentual de las especies de interés apícola relevadas, clasificadas por status. Puede observarse que el $81 \%$ de las especies son nativas, correspondiendo el 19\% restante a exóticas. Estas últimas se discriminan en adventicias, introducidas y naturalizadas; siendo sus valores de 12,5 y $2 \%$, respectivamente. Dentro de las introducidas, 7 corresponden a cultivos.

En la Figura 4 se presenta la distribución porcentual de las especies apícolas relevadas en los sitios de estudio, clasificadas por hábitos. Puede observarse que el mayor porcentaje (74\%) correspondió a hierbas, seguido por los arbustos

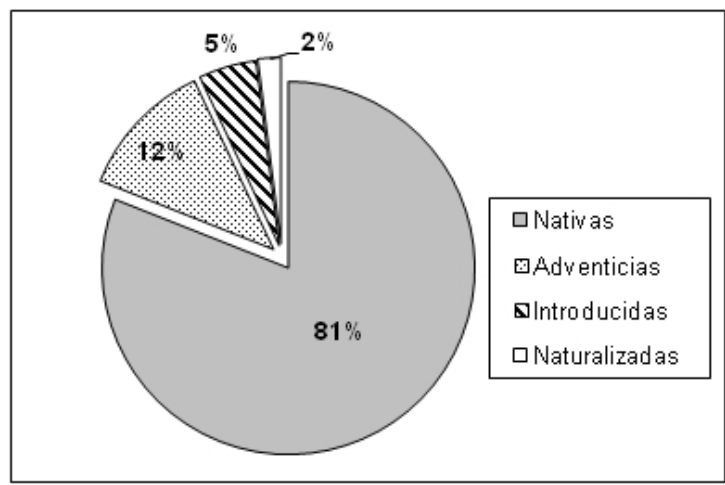

Fig. 3. Distribución porcentual de las especies apícolas relevadas en los sitios de estudio, discriminadas por status. 


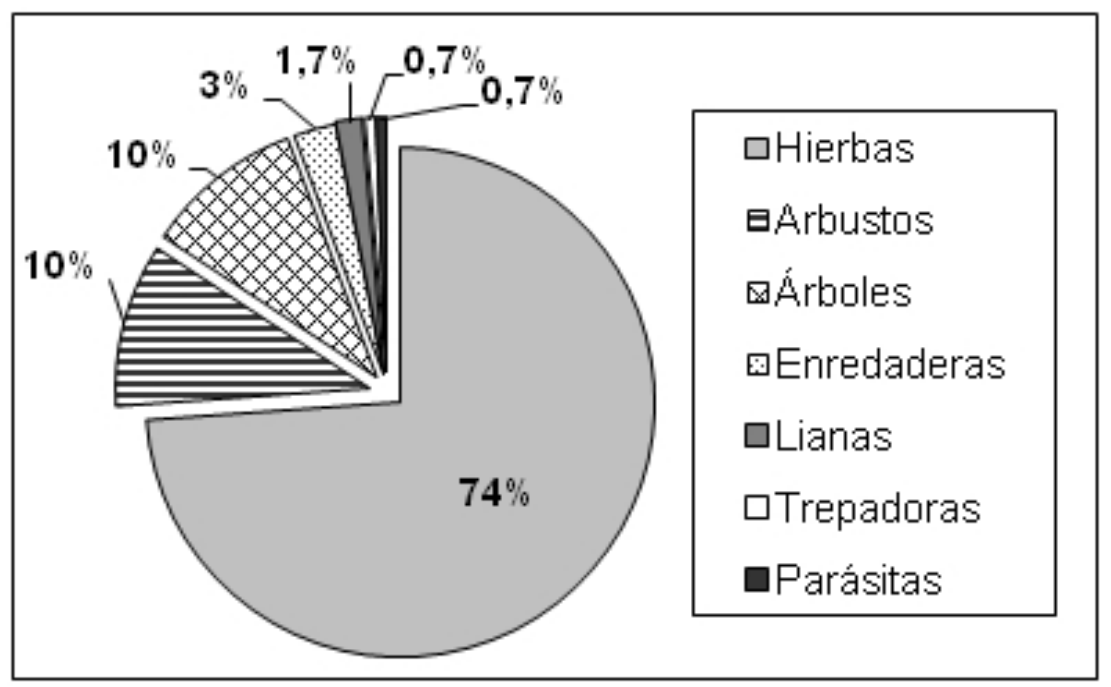

Fig. 4. Distribución porcentual de las especies apícolas relevadas en los sitios de estudio, discriminadas por hábitos.

y los árboles con $10 \%$ cada uno. Las trepadoras representaron el 3\%, las enredaderas el $1.7 \%$, mientras que las parásitas y lianas $0.7 \%$ cada una.

En la Figura 5 se presenta la oferta de floración a lo largo del calendario apícola, de las 299 especies seleccionadas (Tabla 1) en los 3 sitios de muestreo. La temporada apícola en la región se extiende desde agosto-septiembre a abril-mayo dependiendo de las condiciones meteorológicas (temperatura y precipitaciones principalmente). Se observó una abundante floración a lo largo de toda la temporada apícola (primavera-otoño) en cuanto a número de especies en floración. Éstas aumentaron considerablemente a partir de septiembre y se mantuvieron en valores elevados hasta mediados de abril. El período de mayor oferta de floración comprende desde mediados de octubre hasta fin de febrero, con un máximo en la primera quincena de diciembre.

Las especies nativas superaron ampliamente a las de origen exótico a través de todo el período. Las especies exóticas presentaron un pico de floración durante noviembre, en cambio las nativas presentaron 3 picos de floración; el primero en la segunda quincena de septiembre, el segundo en la primera quincena de noviembre, y el tercero y de mayor magnitud, en la primera quincena de enero (Figs. 5 y 6 ).
Las especies herbáceas predominaron sobre las arbóreas/arbustivas a través de todo el período, presentando tres picos de floración, el primero de ellos en la primer quincena de noviembre, el segundo en la primer quincena de diciembre y el último similar al anterior en valores, registrándose en la primer quincena de enero (Fig. 6). Las arbóreas/arbustivas presentaron dos picos de floración; el primero en la segunda quincena de septiembre y el segundo de mayor magnitud, en la segunda quincena de octubre.

El período de disponibilidad de recursos alimenticios para las abejas, fue similar al observado en regiones vecinas como el Delta inferior del río Paraná (Gurini \& Basilio, 1995), o en las ecoregiones Chaco Húmedo (Cabrera et al., 2013; Salgado et al., 2014) y Chaco Seco (Salgado et al., 2014), y levemente más extenso que la registrada para la eco-región Pampa (Tellería, 1993) y áreas melíferas de la Patagonia, como el Valle Inferior del río Chubut (Forcone, 2003), noroeste de Chubut (Forcone \& Kutschker, 2006) y noroeste de Santa Cruz (Forcone \& Muñoz, 2009) o el Distrito del Caldén de la eco-región Espinal (Naab et al., 2001). Las mayores diferencias se presentaron con regiones como el Sur del Caldenal (Andrada, 2003), cuyo periodo se extiende desde primavera a principio de verano. Las diferencias encontradas 


\section{G. Fagúndez et al. - Floración de interés apícola en el SO Entrerriano}

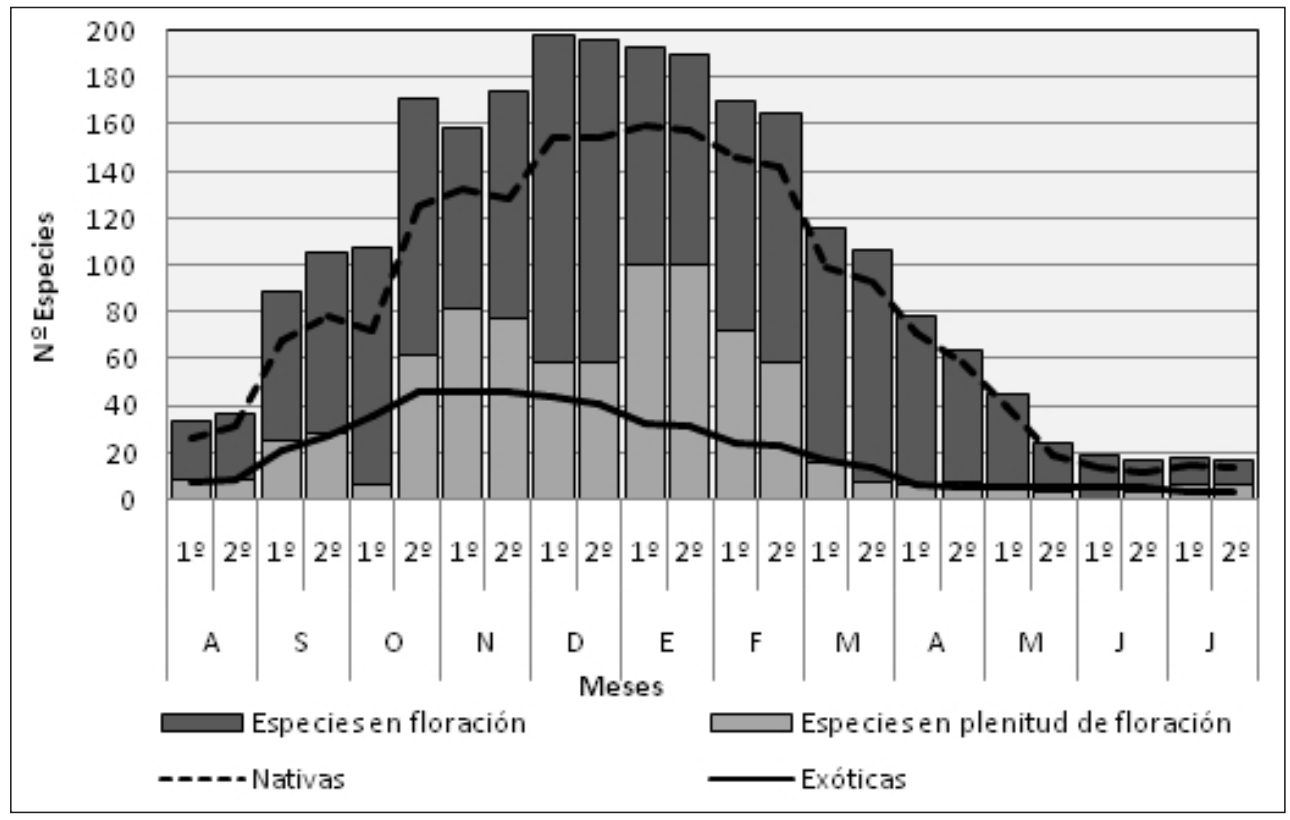

Fig. 5. Oferta de floración en el suroeste de Entre Ríos a lo largo del periodo apícola, discriminadas según status de las especies. ( $1^{\circ}$ y $2^{\circ}$ : quincenas). Se representa el $n^{\circ}$ de especies totales en floración y en plenitud de floración.

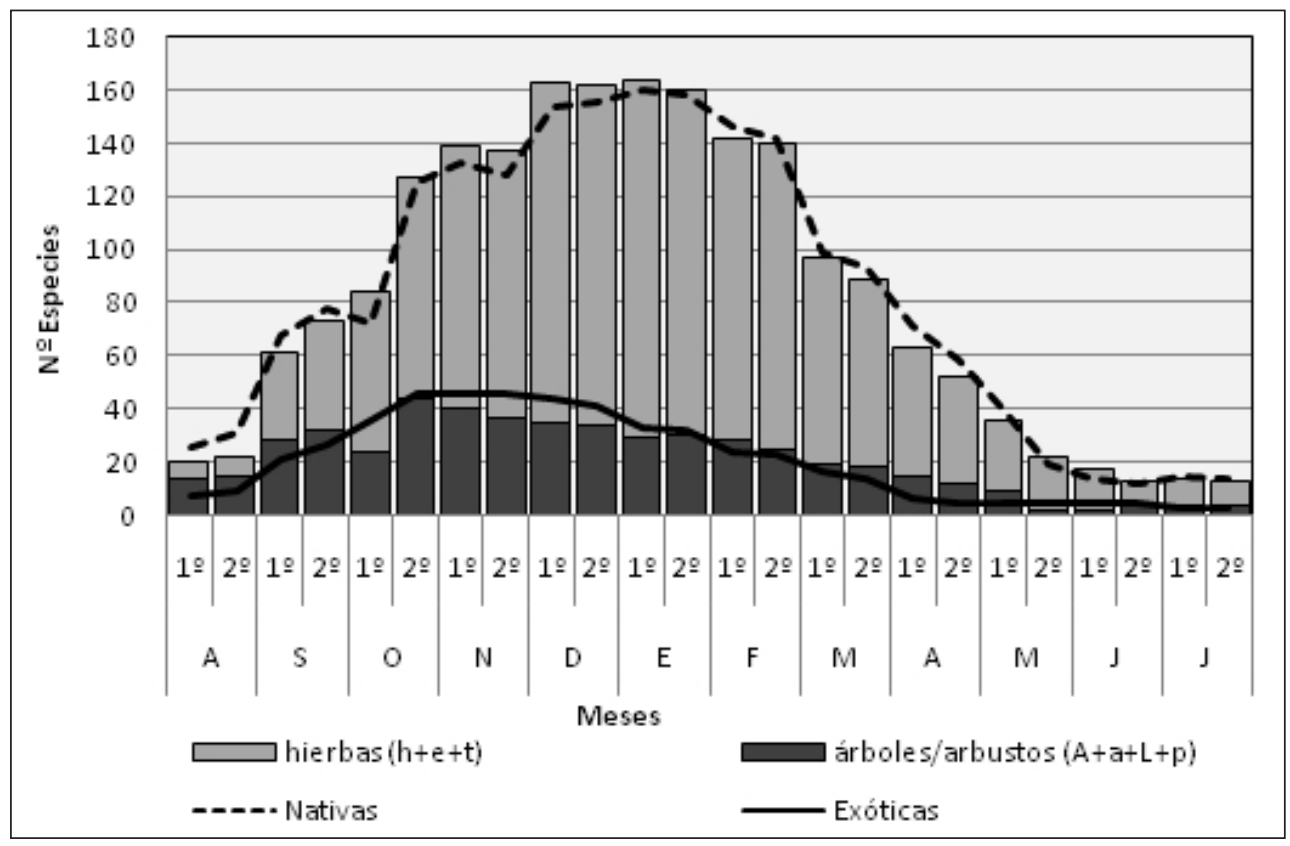

Fig. 6. Oferta de floración en el suroeste de Entre Ríos a lo largo del periodo apícola, discriminadas según status y hábitos de las especies. $\left(1^{\circ}\right.$ y $2^{\circ}$ : quincenas; Hábitos: h, hierba; e, enredaderas; $t$, trepadoras; $\mathrm{A}$, árboles; a, arbustos; L, lianas; $p$, parásitas. Las especies parásitas se hallan asociadas a árboles y las lianas se encuentran en comunidades boscosas, por lo cual se incluyen en la categoría de árboles/arbustos). 
con otras regiones se presentaron tanto a principio de la temporada (muchas especies en floración a fines de invierno), como en su extensión hasta mediados de otoño, favorecidas por las condiciones climáticas reinantes en la región de estudio.

\section{Estimación de abundancia y cobertura}

En la Tabla 1 se presentan, para los ambientes definidos, los índices de abundancia y cobertura de las especies relevadas. No se detallan los valores para los ambientes pasturas implantadas y agrícola, debido a que se trataron de cultivos monoespecíficos ("soja", "maíz", "girasol", "alfalfa", "trébol de cuernitos") con valores de cobertura del 100\%. En el caso de las especies forrajeras se hallaron pasturas polifíticas de Trifolium repens, $T$. pratense y Melilotus albus, cuyos índices varían entre 2-3 y se detallan en el encabezado de la tabla para los diferentes sitios de muestreo y ambientes.

Si bien la oferta de recursos es amplia sólo algunas especies revisten importancia en cuanto a la cobertura. Las familias botánicas entomófilas, más relevantes en la oferta de floración (abundancia) fueron Asteraceae, Fabaceae, Apiaceae y Brassicaceae. Las Asteraceae hacen su aporte en toda la temporada, destacándose las malezas exóticas en primavera. El aporte de Fabaceae se extiende a todo el período, mientras Apiaceae lo hace principalmente en primavera y Brassicaceae en invierno y primavera. Estas familias fueron las más utilizadas por Apis mellifera como recursos nectaríferos (Fagúndez, 2015) y poliníferos (Fagúndez, 2011) en el Departamento.

Se observa una marcada predominancia de especies nativas respecto de las exóticas, pero al considerar la superficie abarcada, pierden importancia debido a que se encuentran en sectores limitados. Esto se contrasta con las características del paisaje del sector de tierra firme del departamento Diamante, el mismo se encuentra cubierto casi en su totalidad por hierbas exóticas implantadas (cereales, oleaginosas y forrajeras) (Zamboni, 2008). En concordancia, Fagúndez (2015) menciona que $A$. mellifera utiliza como recurso nectarífero variada vegetación nativa, la cual predomina en número de especies sobre las exóticas forrajeadas, pero que estas últimas constituyen los recursos más intensamente explotados en la región de tierra firme del departamento.

Las hierbas constituyen mayoritariamente el recurso apícola del departamento. Los árboles pueden ser una importante fuente a principio de primavera en regiones costeras (especies de Salix, Myrcianthes cisplatensis) o en relictos de bosques nativos sobre la franja costera (Acacia caven, A. bonariensis, Geoffroea decorticans, especies de Prosopis y Schinus). Arbustos conocidos como "chilcas" (especies de Baccharis y Eupatorium) realizan un importante aporte a fin del verano. Las especies acuáticas y palustres (Sagittaria montevidensis, especies de Pontederia, Eichhornia y Polygonum) presentes en la región costera e insular del departamento constituyen un valioso recurso durante toda la temporada, permitiendo extender el periodo apícola hasta el otoño (abrilmayo).

Estos aspectos se reflejan en las mieles producidas en dicho departamento (Fagúndez, 2015), predominando (30\%) las de Fabaceae Papilionoideae conocidas como "tréboles" (involucra a Medicago sativa, Lotus corniculatus, Melilotus albus, Trifolium repens y $T$. pratense); se registraron además un alto porcentaje (21\%) de mieles de "soja" (Glycine max), y en menor proporción de Ammi visnaga-A. majus (5\%) y Salix humboldtiana (3\%). A su vez, dichas mieles se caracterizaron por la asociación de polen de especies de Ammi, L. corniculatus, M. albus, G. max, Asteraceae Asteroideae nativas (especies de Baccharis, Eupatorium, Bidens, Solidago chilensis y Grindelia pulchella) y Salix humboldtiana. Asimismo, presentaron abundantes taxones acuáticos o palustres, tales como Sagittaria montevidensis, Tessaria integrifolia, Sapium haematospermum, especies de Polygonum y Eichhornia, tipo Serjania, tipo Ludwigia peploides, Nymphoides indica y Pontederia.

Otros autores han observado predominancia de especies leñosas al principio de la primavera y de herbáceas hacia el final de la misma (Tellería, 1993; Naab et al., 2001; Forcone, 2003, Forcone \& Kutschker, 2006; Forcone \& Muñoz, 2009; Salgado et al., 2014). En el Delta del Paraná también se observó predominancia de especies arbóreas al principio de la temporada (Gurini \& Basilio, 1995), pero a diferencia de las demás regiones de Argentina, éstas son de origen exótico, especialmente cultivadas (especies de Salix, Populus, Quercus y Prunus). En el bosque nativo Formoseño, correspondiente a la eco-región Chaco Húmedo, Cabrera et al. (2013) encontraron predominancia de especies leñosas 


\section{G. Fagúndez et al. - Floración de interés apícola en el SO Entrerriano}

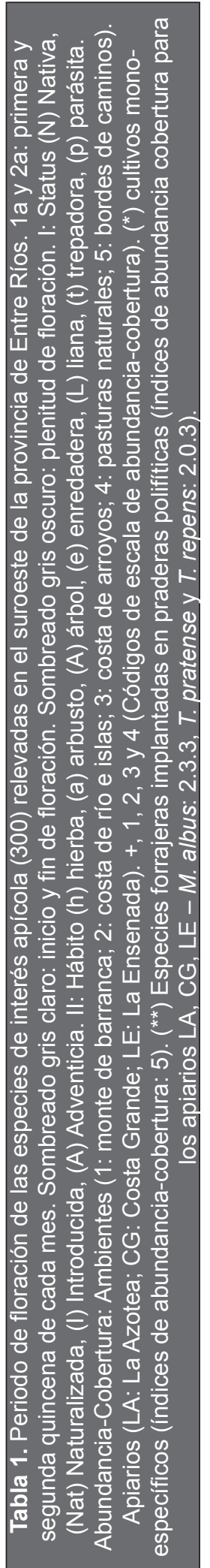

\begin{tabular}{|c|c|c|c|c|c|c|c|c|c|c|c|c|c|c|c|c|c|c|c|c|c|c|c|c|}
\hline \multirow{10}{*}{ 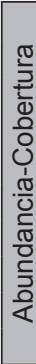 } & щ & 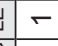 & & & & & & & & $N$ & & 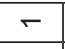 & $\sim$ & $\sim$ & $m$ & $\sim$ & $N$ & 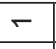 & & & $\begin{array}{ll}N \\
\end{array}$ & & & - \\
\hline & 108 & $\begin{array}{ll}35 \\
\end{array}$ & & & + & & + & & & 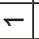 & & + & $r$ & $N$ & $N$ & + & + & + & & & -+ & & & + \\
\hline & 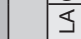 & & & & $r$ & & & & & + & & & 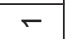 & $N$ & $N$ & & $\tau$ & + & & & $r+$ & & & $r$ \\
\hline & Ш & & & & & & & - & - & $\tau$ & & & & & & $N$ & & $r$ & + & $\tau$ & & & & \\
\hline & +8 & & & & & & + & & & & & & & $N$ & $N$ & $\tau$ & & + & & & $m$ & $r$ & & \\
\hline & 5 & & & & & & & & & & & & & $N$ & $N$ & & & & & & $\sigma$ & & & \\
\hline & m Ш & & & & & - & & & & & & & - & & & & & - & & & $N$ & - & & \\
\hline & $m 8$ & + & & & $N$ & + & & & & - & & - & & & & & & + & & & & - & & $r$ \\
\hline & $N \leq$ & & & & & $m$ & & & & & & & & & & & & & & & & - & & \\
\hline & $-\leq$ & + & + & + & $N$ & & & + & & & + & - & $N$ & - & - & & & + & & $-\sigma$ & - & . & $N$ & \\
\hline & $=$ & $ᄃ$ & ᄃ & . & $<$ & $ᄃ$ & $\simeq$ & ᄃ & ᄃ & 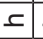 & 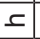 & ᄃ & $\sigma$ & $\simeq$ & $ᄃ$. & ᄃ. & ᄃ & ᄃ & 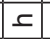 & $ᄃ$. & c. & ع & $\varangle$ & ᄃ \\
\hline & - & $z$ & $z$ & $z$ & $z$ & z & $z$ & $z$ & $z$ & $z$ & $z$ & z & $z$ & $\ll$ & $<$ & $z$ & $\ll$ & z & $z$ & $z$ & $z \mid<$ & $z$ & z & $z$ \\
\hline & \begin{tabular}{|l|l} 
N \\
\end{tabular} & & & & & & & & & & & & & & & & & & & & & & & \\
\hline & r & & & & & & & & & & & & & & & & & & & & & & & \\
\hline & D & & & & & & & & & & & & & & & & & & & & & & & \\
\hline & \begin{tabular}{|l}
\multicolumn{1}{l}{} \\
\end{tabular} & & & & & & & & & & & & & & & & & & & & & & & \\
\hline & $\Sigma$ & & & & & & & & & & & & & & & & & & & & & & & \\
\hline & 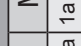 & & & & & & & & & & & & & & & & & & & & & & & \\
\hline & $\ll$ & & & & & & & & & & & & & & & & & & & & & & & \\
\hline & & & & & & & & & & & & & & & & & & & & & & & & \\
\hline & $\Sigma \frac{N}{\sigma}$ & & & & & & & & & & & & & & & & & & & & & & & \\
\hline & & & & & & & & & & & & & & & & & & & & & & & & \\
\hline & $4 \stackrel{\sigma}{\frac{\sigma}{\sigma}}$ & & & & & & & & & & & & & & & & & & & & & & & \\
\hline 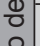 & \begin{tabular}{|c|c} 
& న็ \\
\end{tabular} & & & & & & & & & & & & & & & & & & & & & & & \\
\hline & Ш & & & & & & & & & & & & & & & & & & & & & & & \\
\hline & \begin{tabular}{l|l} 
Nూ \\
\end{tabular} & & & & & & & & & & & & & & & & & & & & & & & \\
\hline & 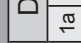 & & & & & & & & & & & & & & & & & & & & & & & \\
\hline & $\stackrel{\pi}{N}$ & & & & & & & & & & & & & & & & & & & & & & & \\
\hline & $z \stackrel{\sigma}{\sigma}$ & & & & & & & & & & & & & & & & & & & & & & & \\
\hline & & & & & & & & & & & & & & & & & & & & & & & & \\
\hline & $0 \longdiv { \sigma }$ & & & & & & & & & & & & & & & & & & & & & & & \\
\hline & & & & & & & & & & & & & & & & & & & & & & & & \\
\hline & の & & & & & & & & & & & & & & & & & & & & & & & \\
\hline & $\stackrel{乛}{\sim}$ & & & & & & & & & & & & & & & & & & & & & & & \\
\hline & $\ll \stackrel{\sigma}{\simeq}$ & & & & & & & & & & & & & & & & & & & & & & & \\
\hline & $\begin{array}{l}\frac{w}{\tilde{w}} \\
\mathbb{d} \\
\frac{0}{w} \\
w\end{array}$ & 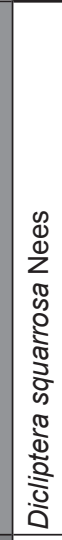 & 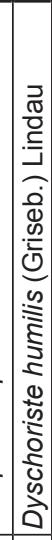 & 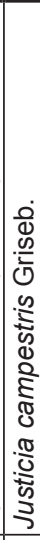 & 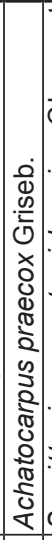 & 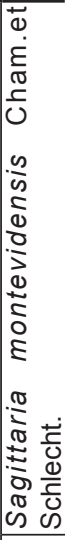 & 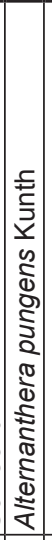 & 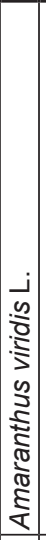 & 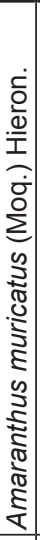 & 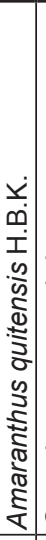 & 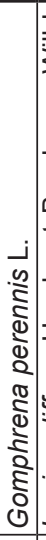 & 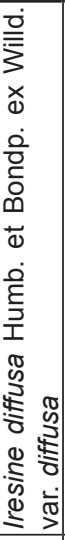 & 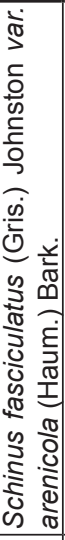 & 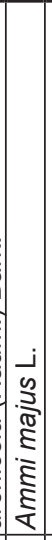 & 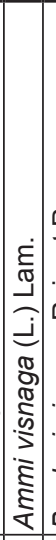 & 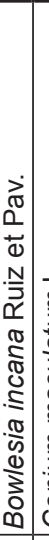 & 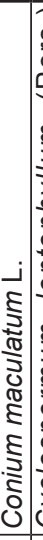 & 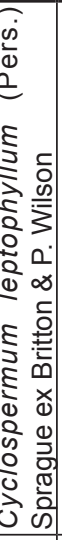 & 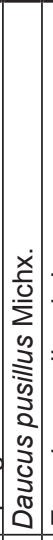 & 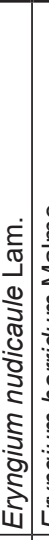 & 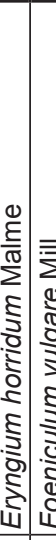 & 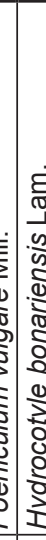 & 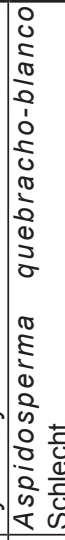 & 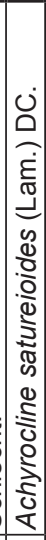 \\
\hline & 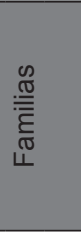 & 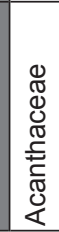 & & & 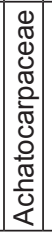 & 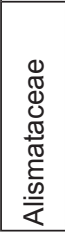 & 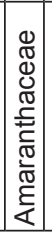 & & & & & & 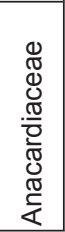 & 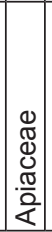 & & & & & & & & & 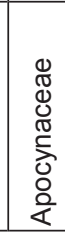 & 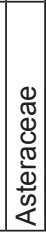 \\
\hline
\end{tabular}


Bol. Soc. Argent. Bot. 51 (2) 2016

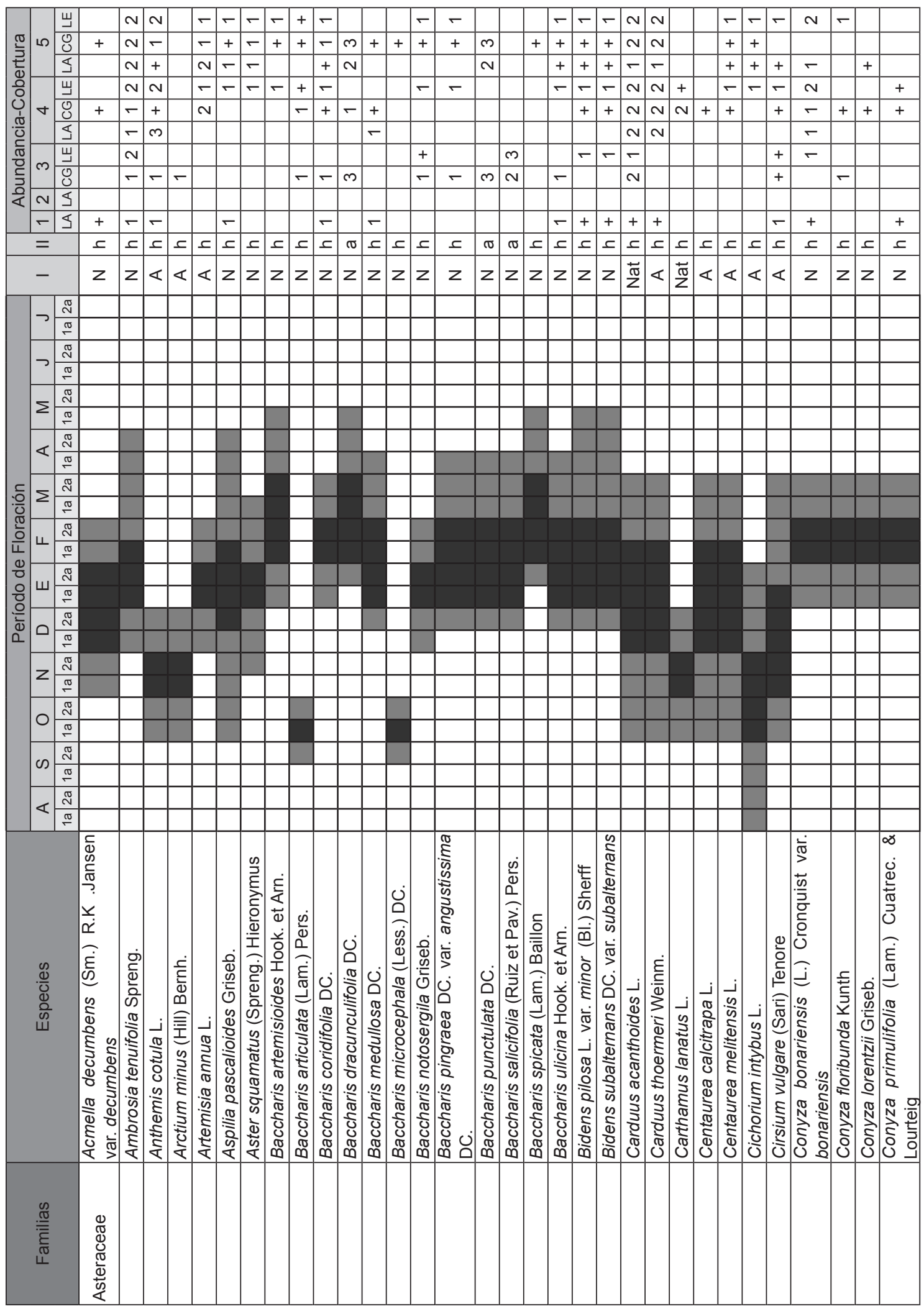


G. Fagúndez et al. - Floración de interés apícola en el SO Entrerriano

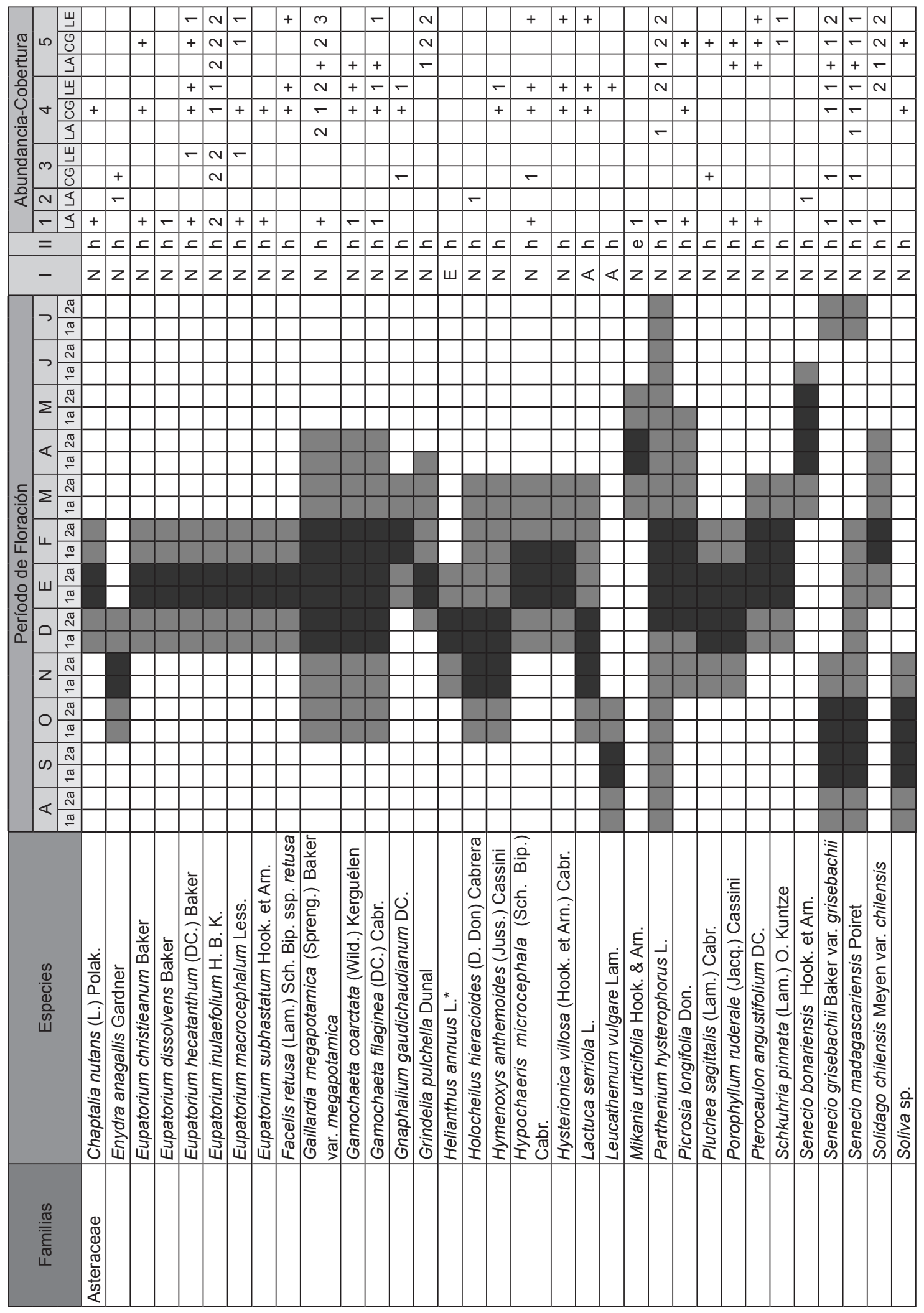


Bol. Soc. Argent. Bot. 51 (2) 2016

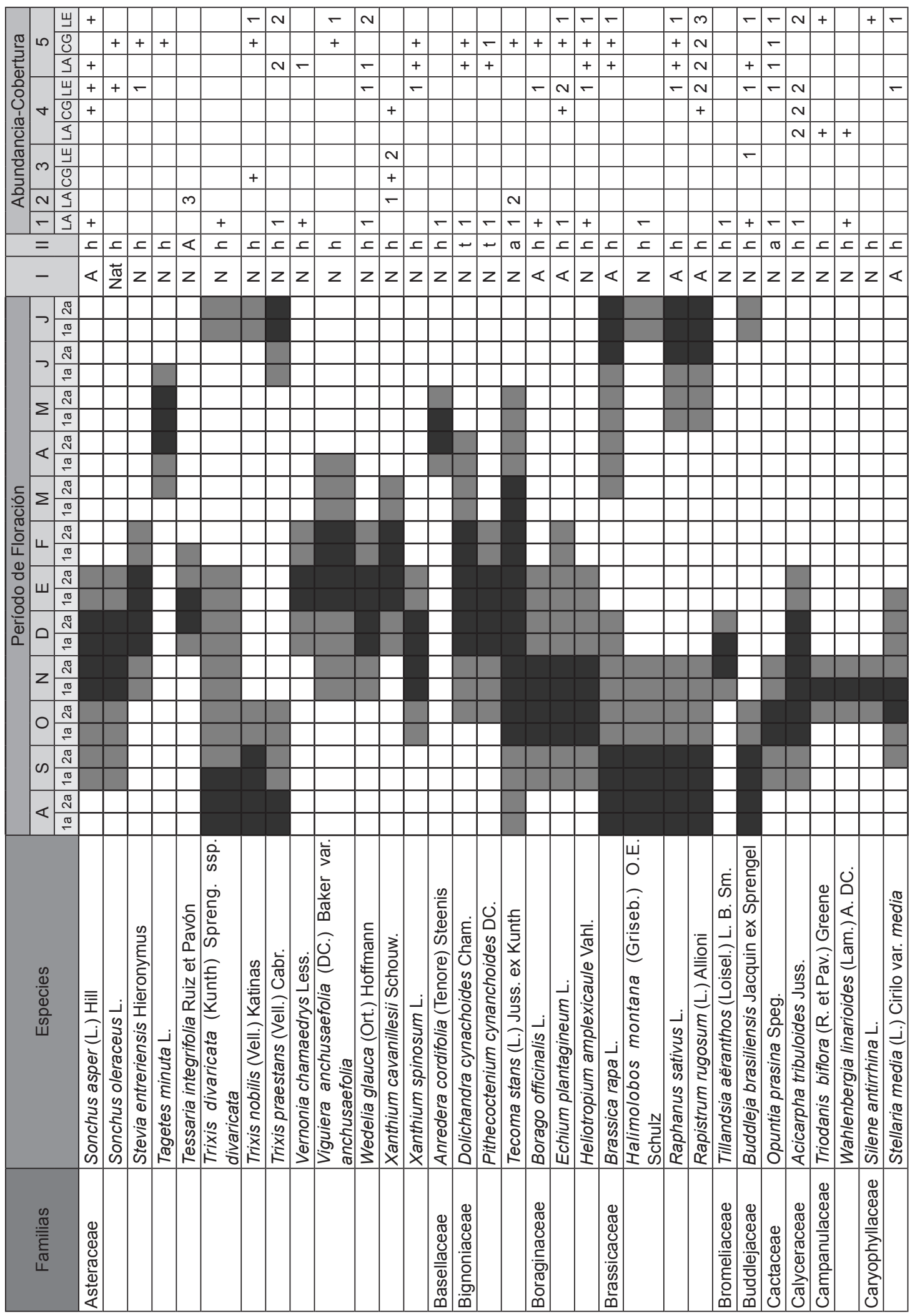


G. Fagúndez et al. - Floración de interés apícola en el SO Entrerriano

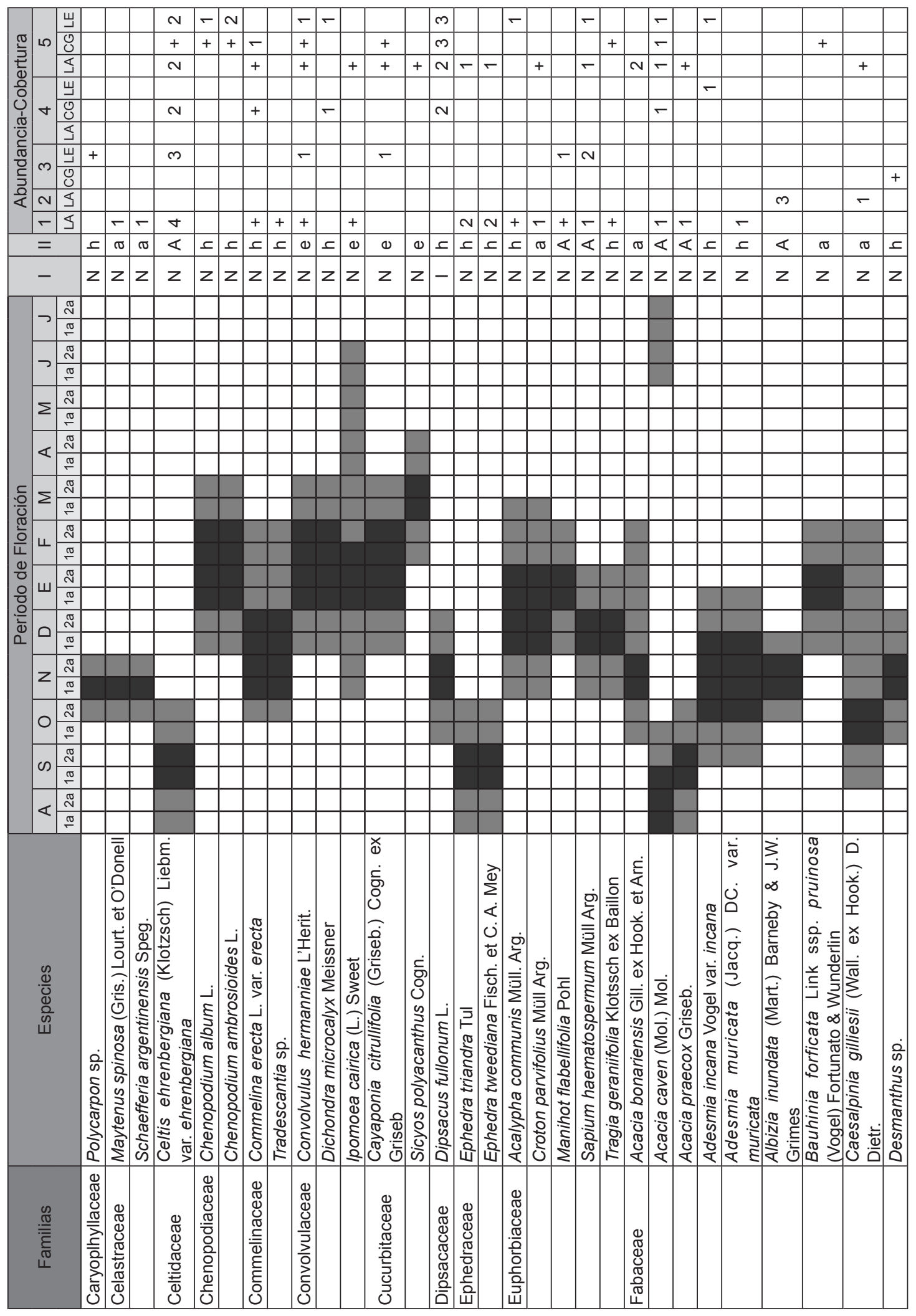


Bol. Soc. Argent. Bot. 51 (2) 2016

\begin{tabular}{|c|c|c|c|c|c|c|c|c|c|c|c|c|c|c|c|c|c|c|c|c|c|c|c|c|c|c|c|}
\hline & 山 & & & & & s & & $N$ & + & & + & & & & & $N$ & $\begin{array}{lll}v & - \\
\end{array}$ & & & + & & $N$ & & -7 & & & \\
\hline$\stackrel{\pi}{=}$ & レ & + & & & & \begin{tabular}{c|c}
$\sigma$ \\
\end{tabular} & $\sqrt{v+}$ & $N$ & $\tau$ & - & & & & & & - & & & & & & $N$ & & & & & \\
\hline ? & 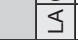 & & $r$ & & & 77 & & + & + & & + & & & & & & + & & & & & \begin{tabular}{l|l} 
& + \\
\end{tabular} & + & 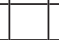 & & & \\
\hline & Ш् & & & & & 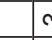 & & - & & & . & & + & & & $N$ & & & & + & + & \begin{tabular}{|l|l}
$N$ & - \\
\end{tabular} & - & - & & & \\
\hline | & $\nabla 0$ & ++ & + & & & - & & + & & & 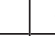 & + & + & & & - & & + & & + & + & & + & - & & +5 & - \\
\hline & $\$$ & & & & & o & & - & & & & & & & & & & $N$ & & & & & & - & & & \\
\hline & \begin{tabular}{l|l} 
\\
\end{tabular} & & & $N$ & & s & & & $N$ & & + & & & & - & & - & & & & & - & & & & & \\
\hline & 0 & o & $N$ & & & & & & + & & & & & & & & - & & + & & + & & & & + & & \\
\hline & $N S$ & & $m$ & & & 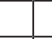 & & & $N$ & & & & & + & - & & & & & & & & & & & & \\
\hline & $-\varangle$ & - & 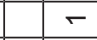 & & & 5 & $-1+$ & + & & - & $N$ & & + & & & & & - & & + & & - & & - & & & \\
\hline & $=$ & $\triangle 5$ & $\varangle$ & $\varangle$ & ᄃ. & $ᄃ \mathrm{sts}$ & 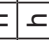 & 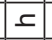 & $\varangle$ & $\varangle$ & $\varangle$ & ᄃ & I & $\pi$ & \begin{tabular}{c|cc}
$\sigma$ & $s$
\end{tabular} & 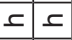 & $=5$ & 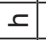 & ᄃ & \begin{tabular}{l|l}
$\subseteq$ & $\subseteq$ \\
\end{tabular} & $ᄃ$ & \begin{tabular}{c|c}
$\subseteq$ & \lrcorner \\
\end{tabular} & 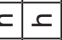 & 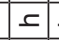 & 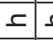 & c & ع \\
\hline & - & $z$ & $z$ & $-L$ & ш. & $-<$ & $<<$ & $<$ & $z$ & $z$ & $z$ & z & z & $z$ & $|z|<$ & $<\mid<$ & $6<1$ & $\varangle$ & $\ll$ & $z \mid z$ & z & $z \mid-$ & -- & $z$ & - & & $z$ \\
\hline & \begin{tabular}{l|l} 
& $\approx$ \\
\end{tabular} & & & & & & & & & & & & & & & & & & & & & & & & & & \\
\hline & $3 \div$ & & & & & & & & & & & & & & & & & & & & & & & & & & \\
\hline & Nָ & & & & & & & & & & & & & & & & & & & & & & & & & & \\
\hline & $\sqrt{\overparen{\sigma}}$ & & & & & & & & & & & & & & & & & & & & & & & & & & \\
\hline & $\stackrel{5}{2}$ & & & & & & & & & & & & & & & & & & & & & & & & & & \\
\hline & $2 \longdiv { \sigma }$ & & & & & & & & & & & & & & & & & & & & & & & & & & \\
\hline & \begin{tabular}{l}
\multirow{N}{*}{} \\
\end{tabular} & & & & & & & & & & & & & & & & & & & & & & & & & & \\
\hline & $\stackrel{\sigma}{\sim}$ & & & & & & & & & & & & & & & & & & & & & & & & & & \\
\hline & $\Sigma \stackrel{\Omega}{N}$ & & & & & & & & & & & & & & & & & & & & & & & & & & \\
\hline & $2 \sqrt{\circ}$ & & & & & & & & & & & & & & & & & & & & & & & & & & \\
\hline & \begin{tabular}{l|l}
\multirow{4}{*}{} & $\approx$ \\
\end{tabular} & & & & & & & & & & & & & & & & & & & & & & & & & & \\
\hline$\overline{1}$ & $4 \longdiv { \sigma }$ & & & & & & & & & & & & & & & & & & & & & & 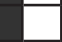 & & & & \\
\hline$\frac{1}{0}$ & 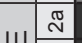 & & & & & & & & & & & & & & & & & & & & & & L & . & & & \\
\hline & 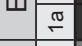 & & & & & & & & & & & & & & & & & & & & & & 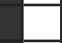 & & & & \\
\hline & N & & & & & & & & & & & & & & & & & & & & & & 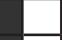 & & & & \\
\hline & & & & & & & & & & & & & & & & & & & & & & & & 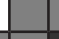 & & & \\
\hline & $z \stackrel{\mathbb{N}}{\Omega}$ & & & & & & & & & & & & & & & & & & & & & & & 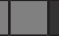 & & 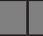 & \\
\hline & $\frac{\frac{\pi}{\pi}}{\frac{\pi}{\pi}}$ & & & & & & & & & & & & & & & & & & & & & & & & & & \\
\hline & 0 & & & & & & & & & & & & & & & & & & & & & & & & & & \\
\hline & $\frac{\pi}{\pi}$ & & & & & & & & & & & & & & 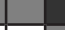 & 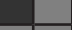 & & & & & & & & & & & \\
\hline & $\frac{\tilde{N}}{\sigma}$ & & & & & & & & & & & & & & & & & & & & & & & & & & \\
\hline & & & & & & & & & & & & & & & & & & & & & & & & & & & \\
\hline & $\stackrel{N}{N}$ & & & & & & & & & & & & & & & & & & & & & & & & & & \\
\hline & $\stackrel{\pi}{-}$ & & & & & & & & & & & & & & & & & & & & & & & & & & \\
\hline & 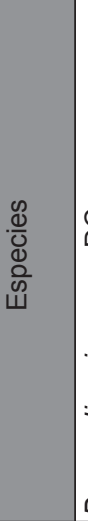 & 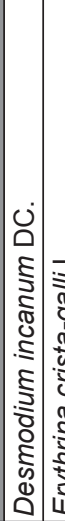 & 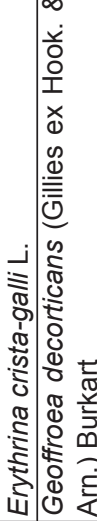 & 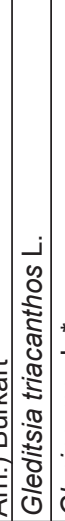 & 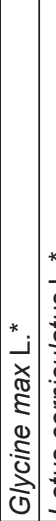 & 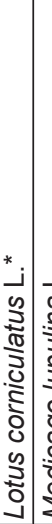 & 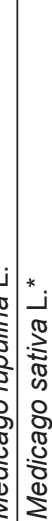 & 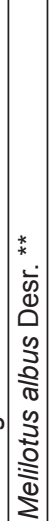 & 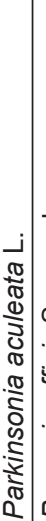 & 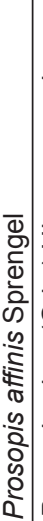 & 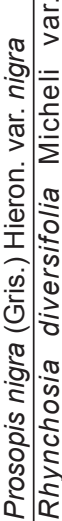 & 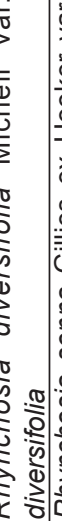 & 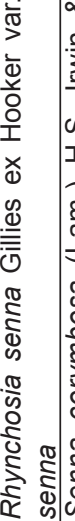 & 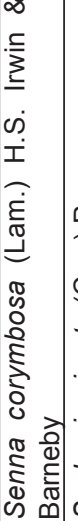 & 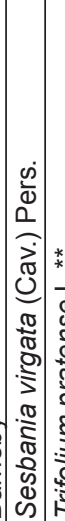 & 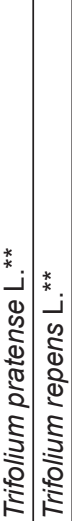 & 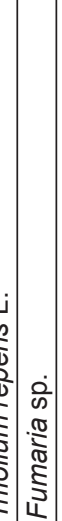 & 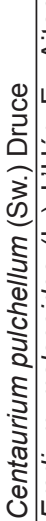 & 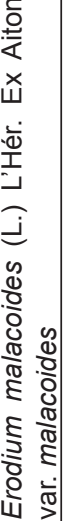 & 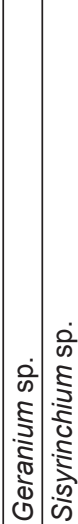 & 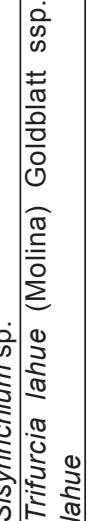 & 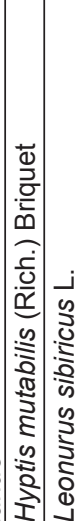 & 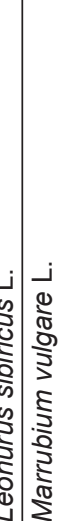 & 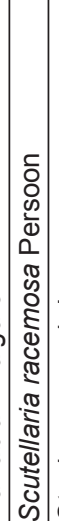 & 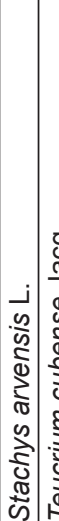 & 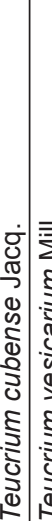 & 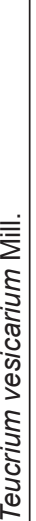 \\
\hline & 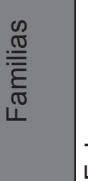 & 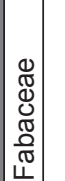 & & & & & & & & & & & & & & & 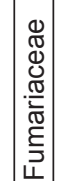 & 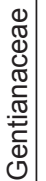 & 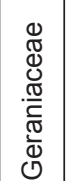 & 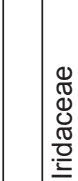 & 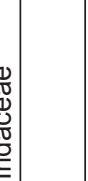 & 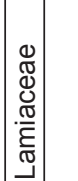 & & & & & \\
\hline
\end{tabular}


G. Fagúndez et al. - Floración de interés apícola en el SO Entrerriano

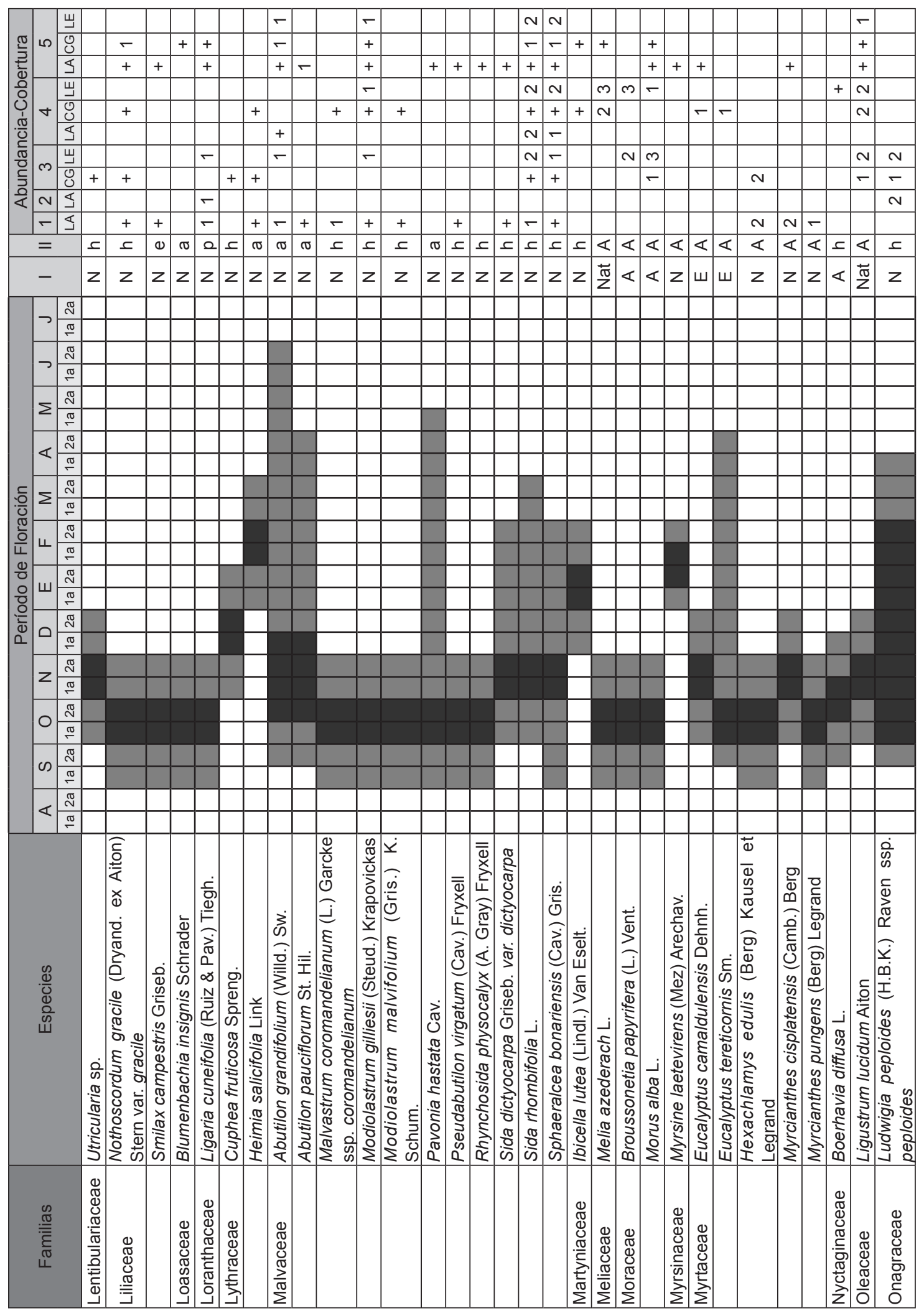


Bol. Soc. Argent. Bot. 51 (2) 2016

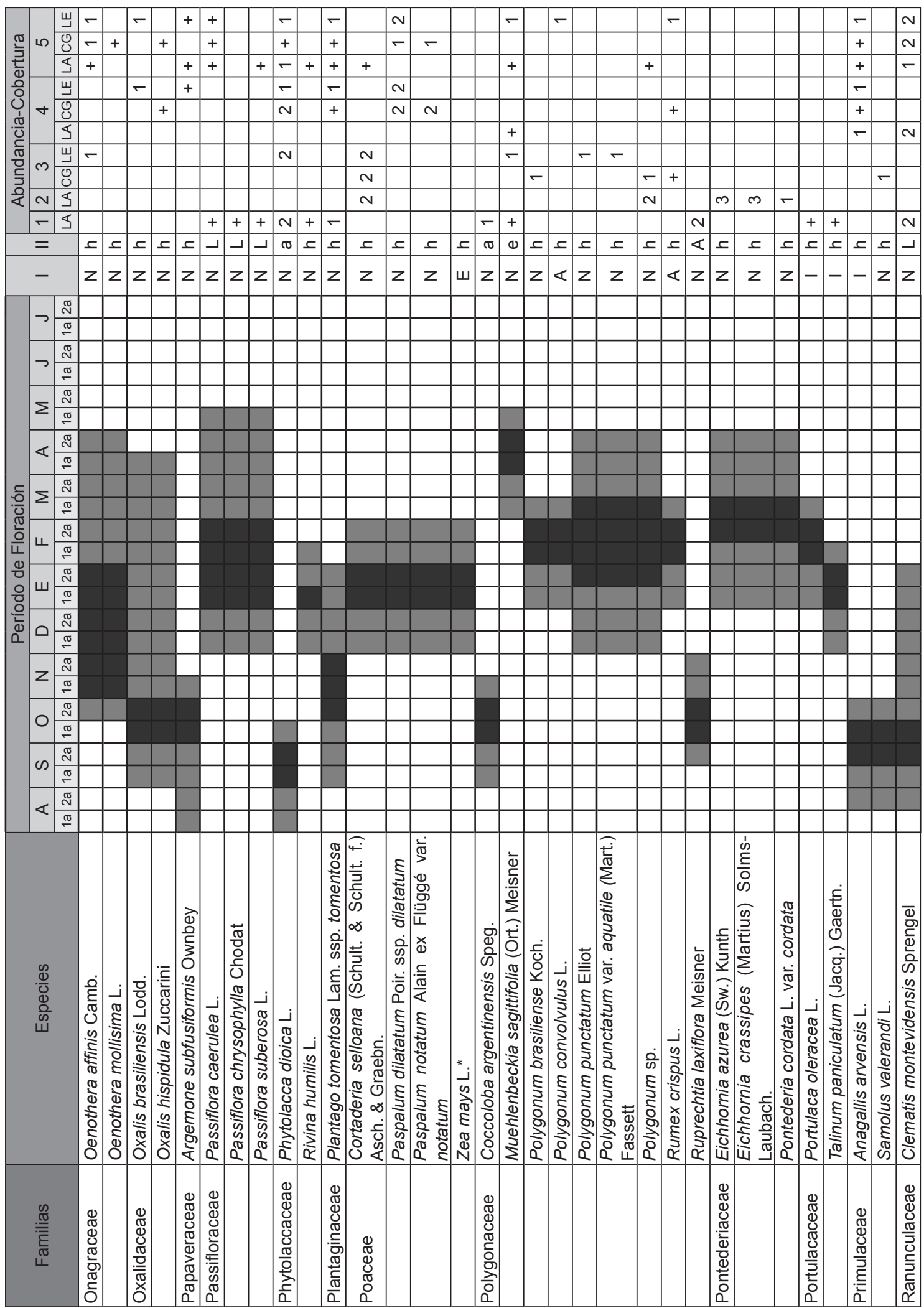


G. Fagúndez et al. - Floración de interés apícola en el SO Entrerriano

\begin{tabular}{|c|c|c|c|c|c|c|c|c|c|c|c|c|c|c|c|c|c|c|c|c|c|c|c|c|c|c|c|c|c|}
\hline & & 凹 & & & & & & & & & & & & & & - & & 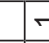 & $-r$ & & & + & + & & - & - & & & \\
\hline$\stackrel{\frac{\pi}{5}}{5}$ & 100 & $\begin{array}{l}0 \\
0 \\
\end{array}$ & & & & & & & & & & & & & & + & 5 & $-r$ & & + & & + & & & + & & & + & \\
\hline$\frac{\vec{t}}{0}$ & & $\mathbb{\Xi}$ & & & & & + & & & + & + & & & & & + & & +7 & & + & & + & & + & & & & & + \\
\hline 용 & 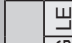 & Ш् & & & & & & & & & & & & 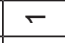 & 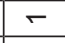 & & & & & & & 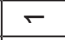 & - & -10 & $N$ & 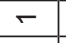 & + & & 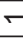 \\
\hline דים & +0 & 0 & & & & & & + & & & L & & 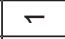 & & & 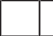 & & + & & & & & & + & & & & & \\
\hline$\frac{\pi}{0}$ & & $\Xi$ & & & & & & & & & & & & & & L & & . & & + & + & + & & + & & & & + & 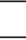 \\
\hline$\frac{\pi}{0}$ & 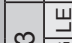 & 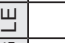 & & & + & & & & $\nabla$ & & - & & & + & + & 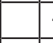 & + & $F$ & $-\sigma$ & & & & & + & & & & 4 & 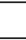 \\
\hline క్ & 8 & \begin{tabular}{l|l} 
\\
0
\end{tabular} & $N$ & & & & & & $N$ & & & & & & & & & + & & & & & & & & & & & \\
\hline & \begin{tabular}{l|l}
$N$ & \\
\end{tabular} & \begin{tabular}{l|l} 
& -
\end{tabular} & & & & - & & & \% & & & & & & & & & & & & & & & & & & & & \\
\hline & -14 & 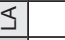 & & + & $\Gamma$ & & - & & & - & + & $N$ & & & & & & $-\sigma$ & 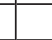 & 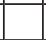 & + & & & -1 & & & + & + & $r$ \\
\hline & $=$ & 5 & $\sigma$ & ᄃ & $\subseteq$ & 5 & 䟚 & $\varangle$ & $\varangle$ & $\varangle$ & -1 & $\varangle$ & $\subseteq$ & 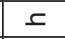 & $ᄃ$ & 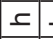 & ᄃ & \begin{tabular}{l|l}
$\sigma$ & $\pi$ \\
\end{tabular} & $\begin{array}{ll}\sigma \\
\sigma\end{array}$ & 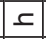 & $ᄃ$ & ᄃ & 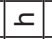 & $\triangle$. & 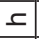 & $ᄃ$ & 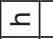 & $\sigma$ & I \\
\hline & - & $z$ & $z$ & $z$ & $z$ & $z$ & $z$ & س & $z$ & $z$ & $z$ & $z$ & z & $z$ & $z$ & $\varangle$ & $<2$ & $z z$ & $z$ & $z$ & $z$ & $z$ & $z$ & $z$ & $z$ & z & $z$ & $z$ & z \\
\hline & \begin{tabular}{|l|c|} 
& $\stackrel{\pi}{N}$ \\
\end{tabular} & న & & & & & & & & & & & & & & & & & & & & & & & & & & & \\
\hline & 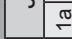 & $\stackrel{\sigma}{\square}$ & & & & & & & & & & & & & & & & & & & & & & & & & & & \\
\hline & \begin{tabular}{|c|c} 
S \\
\end{tabular} & ลี & & & & & & & & & & & & & & & & & & & & & & & & & & & \\
\hline & $\sqrt{\frac{\pi}{4}}$ & $\stackrel{\pi}{\square}$ & & & & & & & & & & & & & & & & & & & & & & & & & & & \\
\hline & 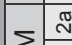 & $\stackrel{\Omega}{\Omega}$ & & & & & & & & & & & & & & & & & & & & & & & & & & & \\
\hline & $1^{2} \div$ & $\stackrel{\pi}{\square}$ & & & & & & & & & & & & & & & & & & & & & & & & & & & \\
\hline & $<\stackrel{2}{N}$ & $\stackrel{\mathbb{N}}{\sim}$ & & & & & & & & & & & & & & & & & & & & & & & & & & & \\
\hline & 4 & $\stackrel{\sigma}{\sim}$ & & & & & & & & & & & & & & & & & & & & & & & & & & & \\
\hline & $\Sigma$ & న్ & & & & & & & & & & & & & & & & & & & & & & & & & & & \\
\hline & 20 & $\stackrel{\sigma}{\square}$ & & & & & & & & & & & & & & & & & & & & & & & & & & & \\
\hline & \begin{tabular}{l|l}
\multirow{2}{*}{} \\
\end{tabular} & ה & & & & & & & & & & & & & & & & & & & & & & & & & & & \\
\hline & $\stackrel{5}{=}$ & 疋 & & & & & & & & & & & & & & & & & & & & & & & & & & & \\
\hline & & $\stackrel{\pi}{N}$ & & & & & & & & & & & & & & & & & & & & & & & & & & & \\
\hline & 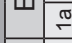 & $\bar{\sigma}$ & & & & & & & & & & & & & & & & & & & & & & & & & & & \\
\hline & \begin{tabular}{|c|c|} 
& \multicolumn{1}{|c}{} \\
\end{tabular} & $\stackrel{\pi}{N}$ & & & & & & & & & & & & & & & & & & & & & & & & & & & \\
\hline & 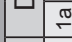 & $\stackrel{\sigma}{-\sigma}$ & & & & & & & & & & & & & & & & & & & & & & & & & & & \\
\hline & $z \stackrel{0}{N}$ & 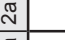 & & & & & & & & & & & & & & & & & & & & & & & & & & & \\
\hline & & $\stackrel{\sigma}{\sim}$ & & & & & & & & & & & & & & & & & & & & & & & & & & & \\
\hline & & న & & & & & & & & & & & & & & & & & & & & & & & & & & & \\
\hline & 0 & $\stackrel{\sigma}{\check{\sigma}}$ & & & & & & & & & & & & & & & & & & & & & & & & & & & t \\
\hline & กั & న & & & & & & & & & & & & & & & & & & & & & & & & & & & \\
\hline & $0)$ & $\stackrel{\sigma}{\square}$ & & & & & & & & & & & & & & & & & & & & & & & & & & & \\
\hline & 4 & ป & & & & & & & & & & & & & & & & & & & & & & & & & & & \\
\hline & 4 & $\begin{array}{l}\sigma \\
\end{array}$ & & & & & & & & & & & & & & & & & & & & & & & & & & & \\
\hline & 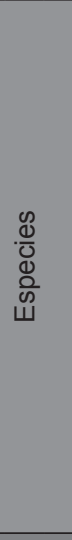 & 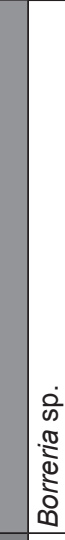 & 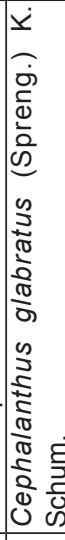 & 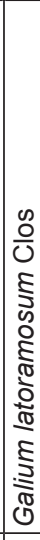 & 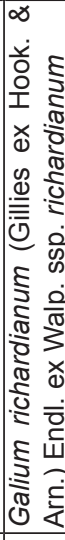 & 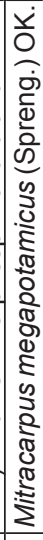 & 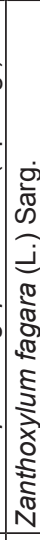 & 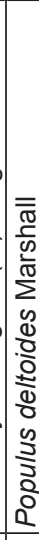 & 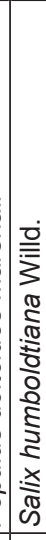 & 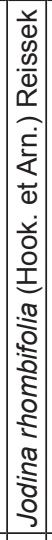 & 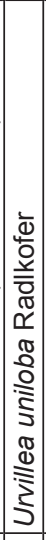 & 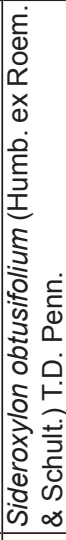 & 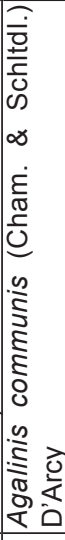 & 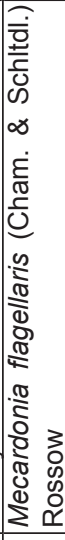 & 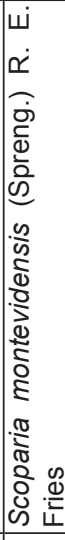 & 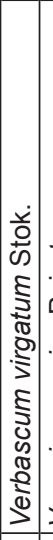 & 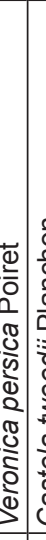 & 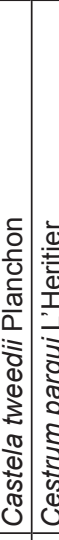 & 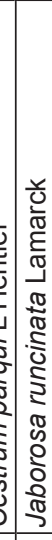 & 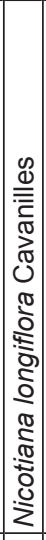 & 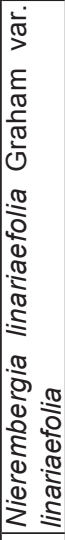 & 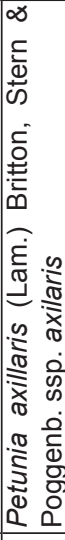 & 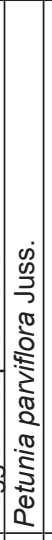 & 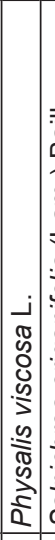 & 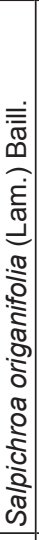 & 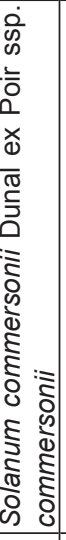 & 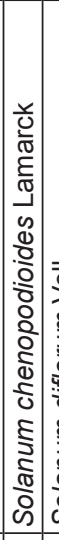 & 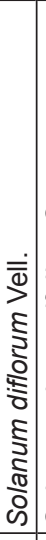 & 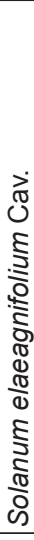 \\
\hline & 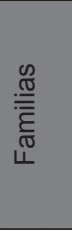 & 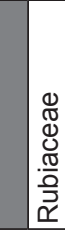 & & & & & 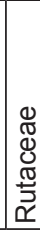 & 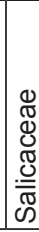 & & 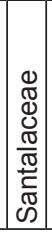 & 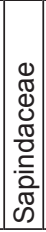 & $\begin{array}{l}0 \\
\mathbb{\pi} \\
\mathbb{0} \\
0 \\
\mathbb{\pi} \\
0 \\
0 \\
\mathbb{0} \\
\infty\end{array}$ & 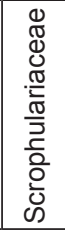 & & & & & 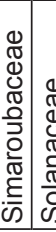 & & & & & & & & & & & \\
\hline
\end{tabular}


Bol. Soc. Argent. Bot. 51 (2) 2016

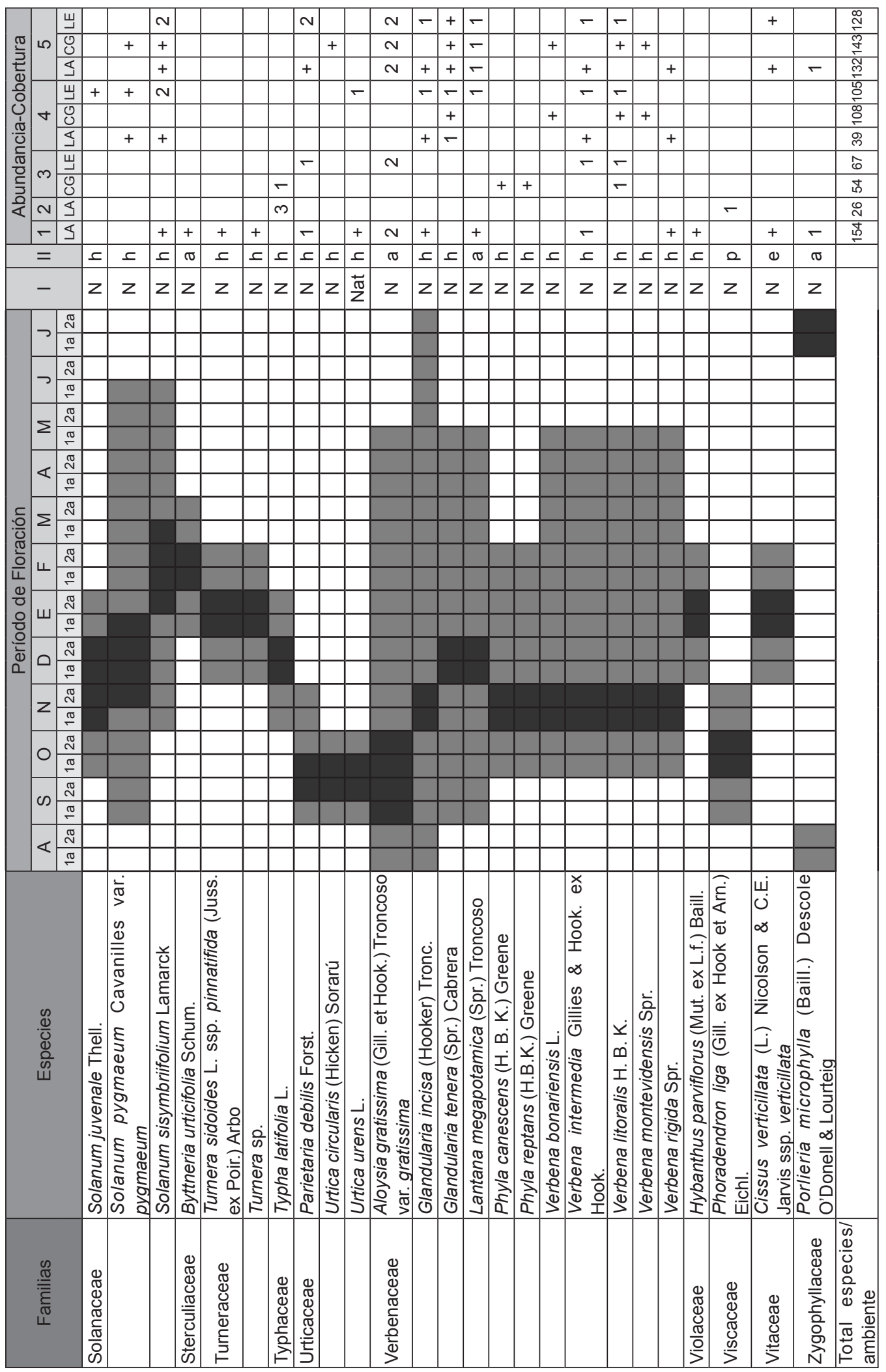




\section{G. Fagúndez et al. - Floración de interés apícola en el SO Entrerriano}

durante todo el periodo apícola, contrariamente a las demás regiones estudiadas de la Argentina. En el presente estudio las herbáceas se destacaron durante toda la temporada. Posiblemente estas diferencias estén relacionadas con las mayores temperaturas presentes en la región y el aumento de precipitaciones a partir de la primavera, que facilitan el desarrollo temprano de las mismas. También se registró floración de algunas leñosas de ambientes acuáticos principalmente hacia mediados y fin de la temporada (Salix humboldtiana, Tessaria integrifolia y Sapium haematospermum). El "sauce criollo" (S. humboldtiana), presentó una segunda floración en el otoño, constituyendo un importante recurso polinífero para las colmenas ubicadas sobre la costa o en islas.

La riqueza específica muestreada fue muy elevada, comparable únicamente con áreas vecinas como el Delta del Paraná (Gurini \& Basilio, 1995), a la cual supera en un $13 \%$. La riqueza hallada en la provincia del Chaco (Salgado et al., 2014) se aproxima a la del presente trabajo, siendo un $21 \%$ inferior; sin embargo debe mencionarse que a diferencia de los restantes trabajos desarrollados en el país, el correspondiente a Chaco comprendió un área muy extensa.

Esta alta riqueza específica relevada en el departamento Diamante se vio reflejada en las mieles producidas (Fagúndez, 2015). En ellas el número de tipos polínicos hallados por muestras fue alto, similar para Argentina únicamente con otras mieles producidas en la provincia de Entre Ríos.

Las demás regiones estudiadas en Argentina, sólo representan desde aproximadamente un sexto del número registrado en el presente estudio, -en la eco-región Monte de Llanuras y Mesetas (Naab \& Tamame, 2007) o Espinal - Dto. Caldén (Naab et al., 2001)- a dos tercios, -en eco-regiones más próximas como la Pampa (Tellería, 1993) o Chaco Húmedo (Cabrera et al, 2013).

Sin embargo, la riqueza específica se reduce al considerar cada sitio de estudio, de 299 especies apícolas, a 211 en el área de influencia del apiario La Azotea, 188 en Costa Grande y 165 en La Ensenada. La similitud entre los sitios, considerando sólo las especies apícolas fue de 0,46 entre LA y CG, 0,38 entre LA y LE, y 0,37 entre CG y LE. Estos valores indican que la composición botánica de los sitios estudiados es diferente, validando la selección de los mismos con el objeto de abarcar la mayor diversidad florística existente en el departamento.

El monte de barranca es el ambiente de mayor riqueza florística. Los bordes de caminos presentan menor riqueza, destacándose la presencia de especies de alto valor apícola como malezas introducidas (Rapistrum rugosum, especies de Carduus, Anthemis cotula, Cichorium intybus, especies de Bidens y Ammi), forrajeras adventicias (Melilotus albus, Lotus corniculatus) y arbustivas nativas (Grindelia pulchella y especies de Baccharis y Eupatorium), con elevada cobertura. Le siguen en orden decreciente los ambientes denominados pasturas naturales. En éstos, se encuentran las especies mencionadas anteriormente, pero con menor cobertura; otras especies melíferas presentes con cobertura relevante son Eryngium horridum y Acicarpha tribuloides. La costa de río e islas, es un ambiente que brinda numerosas especies nativas arbóreas y herbáceas acuáticas o palustres con elevada cobertura (Tabla 1).

Aproximadamente dos tercios de las especies apícolas abordadas en este trabajo, han sido mencionadas en estudios melisopalinológicos y entomopalinológicos llevados a cabo en el Departamento Diamante (Fagúndez \& Caccavari, 2003a; Fagúndez, 2011; Fagúndez, 2015) y en la región (Fagúndez \& Caccavari 2003b, 2006; Caccavari \& Fagúndez, 2010; Fagúndez, 2010; Fagúndez et al., 2012), poniendo de manifiesto la importancia de la flora regional como recurso apícola para Apis mellifera.

\section{Conclusiones}

El suroeste de la provincia de Entre Ríos, posee una flora apícola que se caracteriza por su alta riqueza asociada a la heterogeneidad paisajista de la región. Las especies nativas predominan en número, sin embargo en cuanto a la cobertura espacial, dominan las exóticas (especies agrícolasganaderas implantadas y adventicias).

El periodo de floración se extendió a lo largo de todo el año, con un máximo entre mediados de octubre a fin de febrero.

Las especies arbóreas hacen su aporte principalmente al principio de la temporada, 
siendo ampliamente superadas desde septiembre en adelante por las herbáceas.

El recurso apícola en el sector de tierra firme del departamento, se halla representado principalmente por hierbas exóticas cultivadas y adventicias. En cambio, en el sector costero y de islas, éste se halla conformado por especies nativas acuáticas y palustres, tanto herbáceas como arbóreas. Aparecen especies típicas de ambientes de humedal, que caracterizan y le dan singularidad a la región. Esta vegetación acuática y palustre, permite extender el periodo apícola hacia principios de otoño.

De acuerdo a la información emanada del presente trabajo, un posible esquema de manejo de los apiarios de la zona para optimizar el aprovechamiento de la flora apícola disponible en el departamento y maximizar la producción apícola, consistiría en realizar una trashumancia corta. Este esquema comprende el inicio de la temporada apícola en regiones costeras (monte de barranca, o costa de río e islas), debido al aporte temprano de las especies arbóreas (que proporcionan abundante polen y algunas de ellas también propóleos), que permitirían además de la cosecha de estos productos, la obtención de colonias (núcleos) tempranas (práctica tradicional de multiplicación de colmenas). Asimismo, estas regiones son aptas para la obtención de núcleos tardíos ya que la floración a fin del verano de arbustivas nativas conocidas como "chilcas" (especies de Baccharis y Eupatorium), o la floración extendida hacia el otoño de las especies acuáticas, así como una segunda floración del "sauce criollo" proporcionan abundante néctar y polen al final de la temporada apícola.

Durante el verano la oferta de recursos del monte de barranca declina, siendo conveniente el traslado de las colmenas hacia cualquiera de los otros ambientes (praderas artificiales, agrícolas, costa de río e islas) -si no se presentan en el radio de libación de las mismas- para mantener un adecuado desarrollo y producción de miel.

También podría realizarse una trashumancia enfocada en la obtención de mieles de diferentes orígenes botánicos. El esquema durante el periodo apícola sería: en primavera producción de mieles de especies de Ammi, primavera-verano "tréboles" (Lotus corniculatus, Medicago sativa, Melilotus albus), verano Glycine max, fin de verano-ppio. otoño especies de Baccharis y Salix humboldtiana .

\section{Agradecimientos}

Los autores desean expresar su agradecimiento a los productores que facilitaron el acceso a los predios para los relevamientos. Al Téc. Agr. Guillermo Martínez por su colaboración en tareas de campo. Al PTC Raúl D’Angelo por el procesamiento de las imágenes satelitales. A Paula Barbero por su colaboración en la actualización taxonómica. A Martín Sánchez por la edición del mapa y a los revisores anónimos por sus observaciones y sugerencias que permitieron mejorar la versión final de este trabajo. El presente estudio fue financiado por el CONICET.

\section{Bibliografía}

ACEÑOLAZA, P., H. POVEDANO, A. MANZANO, J. MUÑOZ, J. ARETA \& A. RONCHI VIRGOLINI. 2004. Biodiversidad del Parque Nacional Pre-Delta. En: Temas de la Biodiversidad del Litoral Fluvial Argentino. INSUGEO Miscelánea 12: 169-184.

ACEÑOLAZA, P., L. P. ZAMBONI, W. SIONE \& F. KALESNIK. 2008. Caracterización de la región superior del Complejo Litoral del Río Paraná: grandes unidades de ambiente. En: Temas de la Biodiversidad del Litoral Fluvial Argentino III. INSUGEO Miscelánea 17: 293- 308.

ACEÑOLAZA, P. G. \& E. E. RODRIGUEZ. 2013. Humedales de los tributarios entrerrianos al complejo litoral del Delta del Paraná. En: Laura Benzaquén et. al. (Ed.). "Inventario de los Humedales de Argentina. Sistemas de paisajes de humedales del Corredor Fluvial Paraná-Paraguay". Secretaría de Ambiente y Desarrollo Sustentable de la Nación- $1^{\text {a }}$ ed. Buenos Aires.

ANDERSON, E. \& L. HUBRITCH. 1940. A method for describing and comparing blooming-season. $B$. Torrey Bot. Club 67: 639-649.

ANDRADA, A., A. VALLE, E. ARAMAYO, S. LAMBERTO \& M. CANTAMUTTO. 1998. Análisis polínico de las mieles de las sierras australes de la provincia de Buenos Aires, Argentina. Invest Agr: Prod. Prot. Veg. 13: 265-275.

ANDRADA, A., A. VALLE, E. ARAMAYO, L. GALLEZ. \& S. LAMBERTO. 1999. Caracterización de las mieles del sector meridional del distrito pampeano austral. Asociación Paleontológica Argentina. X Simposio Argentino de Paleobotánica y Palinología. Asociación Paleontológica Argentina. Publicación Especial 6: 71-75.

ANDRADA, A. 2003. Flora utilizada por Apis mellifera 


\section{G. Fagúndez et al. - Floración de interés apícola en el SO Entrerriano}

L. en el sur del Caldenal (Provincia Fitogeográfica del Espinal). Revista Mus. Argen. Cienc. Nat. 5: 329-336.

ARAMAYO, E. A., A. VALLE, A. ANDRADA \& S. LAMBERTO. 1993. Calendario de floración de árboles y especies espontáneas frecuentes en Bahía Blanca. Parodiana 8: 265-270.

BASILIO, A. M. 1996. Polen de las especies hidrófilas en las mieles del Delta del río Paraná (Argentina). Bol. Soc. Argent. Bot. 31: 231-234.

BASILIO, A. M. 1998. Estudio melitopalinológico de los recursos alimentarios y de la producción de un colmenar en la región del Delta del Paraná (Argentina). Tesis Doctoral. Universidad de Buenos Aires, Buenos Aires.

BASILIO, A. \& E. ROMERO. 1996. Contenido polínico de las mieles de la región del Delta del Paraná (Argentina). Darwiniana 34: 113-120.

BOLSA DE CEREALES DE ENTRE RÍOS. 2016. Disponible en: http://www.bolsacer.org.ar/Fuentes/ estadisticas.php. [Acceso 15 de octubre de 2014 y 08 de marzo de 2016].

BRAUN-BLANQUET, J. 1979. Fitosociología. Bases para el estudio de las comunidades vegetales. Blume Ediciones, Madrid.

BURKART, A. 1969. Flora ilustrada de Entre Ríos (Argentina). Parte II: Gramíneas. La familia botánica de los pastos. Ediciones INTA.

BURKART, A. 1974. Flora ilustrada de Entre Ríos (Argentina). Parte VI. Dicotiledóneas Metaclamídeas (Gamopétalas) B: Rubiales, Cucurbitales, Campanulales (incluso Compuestas). Ediciones INTA.

BURKART, A. 1979. Flora ilustrada de Entre Rios (Argentina). Parte V. Dicotiledóneas Metaclamídeas (Gamopétalas), A: Primulales a Plantaginales. Ediciones INTA.

BURKART, A. \& N. BACIGALUPO. 2005. Flora ilustrada de Entre Rios (Argentina). Parte IV. Dicotiledóneas Arquiclamídeas B: Geraniales a Umbelliflorales. Ediciones INTA.

BURKART, A., N. TRONCOSO \& N. BACIGALUPO. 1987. Flora ilustrada de Entre Ríos (Argentina). Parte III: Dicotiledóneas, Arquiclamídeas. A: Salicales a Rosales (incluso Leguminosas). Ediciones INTA.

BURKART, R., N. O. BÁRBARO, R. O. SÁNCHEZ \& D. A. GÓMEZ. 1999. Eco Regiones de la Argentina. Secretaría de Recursos Naturales y Desarrollo Sustentable. Administración de Parques Nacionales. Programa Desarrollo Institucional Ambiental.

CABRERA, A. L. \& E. M. ZARDINI. 1978. Manual de la flora de los alrededores de Buenos Aires. Ed. ACME. Buenos Aires.

CABRERA, A. L. 1976. Enciclopedia Argentina de
Agricultura y Jardinería. Fascículo I. Regiones Fitogeográficas Argentinas; Segunda edición, ACME, Buenos Aires.

CABRERA, M., A. ANDRADA \& L. GALLEZ. 2013. Floración de especies con potencial apícola en el Bosque Nativo Formoseño, Distrito Chaqueño Oriental (Argentina). Bol. Soc. Argent. Bot. 48: 477-491.

CACCAVARI, M. \& G. FAGÚNDEZ. 2010. Pollen spectrum of honeys from the Middle Delta of the Paraná River (Argentina) and their environmental relationship. Span. J. Agric. Res. 8: 42-52.

CARTA DE SUELOS DE LA REPÚBLICA ARGENTINA. 1991. Departamento Diamante, Provincia de Entre Ríos.

COSTA DE BRINGAS, C. 1982. Contribución al conocimiento de la flora melífera de la provincia de Córdoba I, Dpto. Río Segundo. Bol. Soc. Argent. Bot. 21: 247-258.

COSTA DE BRINGAS, C., N. DECOLATTI \& F. GODOY. 1995. Análisis polínico en mieles del norte de la provincia de San Luis. Kurtziana 24: 133-144.

DÍAZ LOSADA, E., A. V. GONZÁlEZ PORTO, E. FERNÁNDEZ GÓMEZ \& M. P. SAA OTERO. 1995. Contribución al estudio de la utilización selectiva por Apis mellifera L. de la flora local en un colmenar del NW de la Península Ibérica (Galicia). Acta Bot. Malac. 20: 115-122.

FAGÚNDEZ, G. A. 2010. Mapas de preferencia apícola Departamentos Gualeguaychú e Islas del Ibicuy (Entre Ríos). Resultados preliminares. Espacio apícola 93: 4-11.

FAGÚNDEZ, G. 2011. Estudio de los recursos nectaríferos y poliníferos utilizados por Apis mellifera L. en diferentes ecosistemas del departamento Diamante (Entre Ríos). Tesis Doctoral. UNS. Bahía Blanca.

FAGÚNDEZ, G. 2015. Botanical and geographical characterisation of honeys in Diamante, Entre Ríos, Argentina. Palynology. (publicado on line). DOI: 10.1080 / 01916122.2015 .1045994$.

FAGÚNDEZ, G. A. \& M. A. CACCAVARI. 2003a. Primeros registros de mieles monofloras y cargas de polen de soja (Glycine max L.) en Argentina. Boletín Apicola Trimestral, SAGPyA 24: 3-6.

FAGÚNDEZ, G. A. \& M. A. CACCAVARI. 2003 b. Caracterización polínica y organoléptica de algunas mieles monofloras del centro de la provincia de Entre Ríos, Argentina. Polen 12: 77-95.

FAGÚNDEZ, G. A. \& M. A. CACCAVARI. 2006. Pollen analysis of honeys from the central zone of Argentine province of Entre Ríos. Grana 45: 305-320.

FAGÚNDEZ, G., A. TROSSERO, P. BARBERO, C. TRUJILLO, M. BERTOS \& D. BLETTLER. 2012. Análisis palinológico y colorimétrico de Mieles del 
Departamento Colón (Entre Ríos). Actas del XV Simposio Argentino de Paleobotánica y Palinología. Corrientes.

FERRARI, C., H. CURRAO \& J. FÓLGAR BESSONE. 2011. La Apicultura Argentina y sus regiones. Una visión panorámica. (Otero, R. \& Collia, J. Coord.). 1ed. Buenos Aires: Consejo Federal de Inversiones.

FORCONE, A. 2003. Plantas nectaríferas utilizadas por Apis mellifera L. en la Patagonia extra-andina, Argentina. Revista Mus. Argent. Cienc. Nat. 5: 363369.

FORCONE, A. \& A. KUTSCHER. 2006. Floración de las especies de interés apícola en el noroeste de Chubut, Argentina. Rev. Mus. Argent. Cienc. Nat. 8: 151-157.

FORCONE, A. \& M. MUÑOZ. 2009. Floración de las especies de interés apícola en el noroeste de Santa Cruz. Bol. Soc. Argent. Bot. 44: 393-403.

GVOZDENOVICH, J., G. PAUSICH \& A. PIOTO. 2015. Relevamiento del uso y cobertura del suelo en la provincia de Entre Ríos a noviembre de 2014. Informe técnico interno INTA RIAN EEA Paraná. Comunicación personal.

GURINI, L. \& A. BASILIO. 1995. Flora apícola en el Delta del Paraná. Darwiniana 33: 337-346.

INDEC (Instituto Nacional de Estadística y Censos) República Argentina. 2016. CNA (Censo Nacional Agropecuario 2002). Disponible en: http://www. indec.mecon.gov.ar/agropecuario/cna2_index. asp? mode $=30$ [Acceso 8 de abril de 2016].

IRIONDO M. 2004. The littoral complex at the Paraná mouth. Quat. Int. 114: 143-154.

JOZAMI, J. M. \& J. d. D. MUÑOZ. 1984. Árboles y Arbustos Indígenas de la Provincia de Entre Ríos. IPNAYS (CONICET-UNL).

LUSARDI, M., A. SCANDIZZI, J. Mc CARGO, S. GATUSSO, L. ARDUSS \& C. CRISCI. 2001. Calendario de Floración de especies frecuentes en la ciudad de Rosario (Santa Fe, Argentina). Arch. Alerg. Inmunol. Clin. 32: 93-97.

McCUNE, B. \& J. B. GRACE. 2002. Analysis of Ecological Communities. MjM, Gleneden Beach, Oregon, USA.

MORELLO, J., S. D. MATTEUCCI, A. F. RODRÍGUEZ \& M. E. SILVA. 2012. Ecorregiones y complejos ecosistémicos argentinos. GEPAMA-FADU-UBA. Orientación Grafica Editora.

MPPER (Ministerio de la Producción, Provincia de Entre Ríos). 2014. Apicultura-Dirección de Lechería y Granja. Producción Apícola de Entre Ríos. Informe estadístico temporada 2009-2010. Disponible en: http:/www.entrerios.gov.ar/minpro/userfiles/files/ PRODUCCION\%20ANIMAL/APICULTURA/ ESTADISTICA/produccion_apicola_entre rios_2010.pdf [Acceso 18 octubre 2014].
MUÑOZ, J. d. D. 1991. En INTA: Carta de Suelos de la República Argentina, Departamento Diamante, Provincia de Entre Ríos.

NAAB, O. A., M. A. CACCAVARI, H. TROIANI \& A. PONCE. 2001. Melisopalinología y su relación con la vegetación en el departamento de Utracán, La Pampa, Argentina. Polen 11: 99-113.

NAAB, O. \& M. A. TAMAME. 2007. Flora apícola primaveral en la región del Monte de la Provincia de La Pampa (Argentina). Bol. Soc. Argent. Bot. 42: 251-259.

PARODI, L. \& M. J. DIMITRI. 1972. Enciclopedia Argentina de Agricultura y Jardinería. 2a. edición. Ed. ACME. Buenos Aires.

PRIMOST, D., G. STAMATTI, N. MESSINA, M. BUZZATTO, L. CARBONI \& R. PÉREZ. 2013. Manual para cursos de Iniciación y Nivelación en Apicultura. Serie de Extensión $N^{o}$ 112. ISSN 03258874. Ediciones INTA.

SALGADO, C. 2006. Flora melífera en la provincia del Chaco. Gobierno de la Provincia de Chaco. Ministerio de la Producción, PROSAP (Programa de Servicios Agrícolas Provinciales), Préstamo BIRF4150/AR.

SALGADO, C. R. \& S. M. PIRE. 1998. Análisis polínico de mieles del noroeste de la provincia de Corrientes (Argentina). Darwiniana 36: 87-93.

SALGADO, C. R. \& S. M. PIRE. 1999. Contribución al conocimiento del contenido polínico de mieles de Corrientes, Argentina. X Simposio Argentino de Paleobotánica y Palinología. Asociación Paleontológica Argentina. Publicación Especial 6: 95-99.

SALGADO, C. R., G. PIESZKO \& TELLERÍA, M. C. 2014. Aporte de la Melisopalinología al conocimiento de la flora melífera de un sector de la provincia fitogeográfica Chaqueña, Argentina. Bol. Soc. Argent. Bot. 49: 513-524.

SODERSTROM, T. R. \& C. E. CALDERON. 1971. Insect pollination in tropical rain forest grasses. Biotropica 3: 1-16.

TAMAME, M. A. 2011. Estudio de la composición, disponibilidad y calidad de los recursos apícolas del Nordeste de la Pampa, provincia fitogeográfica del Monte (República Argentina). Tesis doctoral. Universidad Nacional de la Plata.

TELLERÍA, M.C. 1988. Analyse pollinique des miels $\mathrm{du}$ nord-ouest de la province de Buenos Aires (République Argentine). Apidologie 19: 275-290.

TELLERÍA, M.C. 1992. Caracterización botánica y geográfica de las mieles de la provincia fitogeográfica pampeana (República Argentina) I: Distrito Oriental. Darwiniana 31: 341-350.

TELLERÍA, M.C. 1993. Floración et récolte du pollen par les abeilles domestiques (Apis mellifera L. var. 


\section{G. Fagúndez et al. - Floración de interés apícola en el SO Entrerriano}

ligustica) dans la pampa argentine. Apidologie 24: 109-120.

TELLERÍA, M. C. 1995. Plantas de importancia apícola del Distrito Oriental de la Región Pampeana (Argentina). Bol. Soc. Argent. Bot. 30: 131-136.

TELLERÍA, M. C. 1996a. Caracterización botánica y geográfica de las mieles de la Provincia Fitogeográfica Pampeana (República Argentina), II: Tandilia. Bol. Soc. Argent. Bot. 32: 91-94.

TELLERÍA, M. C. 1996b. Caracterización botánica y geográfica de las mieles de la Provincia Fitogeográfica Pampeana (República Argentina) III: Noreste de la Provincia de La Pampa. Darwiniana 34: 245-249.

TROPICOS. Missouri Botanical Garden [online]. Disponible en http://www.tropicos.org Acceso: 10 de noviembre de 2010].

YOUSSEF, A. M., R. S. FARAG, M. A. EWIES \& M. A. EL-SHAKAA. 1978. Chemical studies on pollen collected by honeybee in Giza region, Egypt. J. Apic. Res. 17: 110-113.

ZAMBONI, L. P. 2008. Diagnóstico y propuesta de ordenación territorial para Diamante (Entre Ríos, Argentina). Tesis para obtener el Título de Máster Universitario. VIII Maestría en Conservación y Gestión del Medio Natural. Universidad Internacional de Andalucía (España).

ZULOAGA, F. O. \& O. MORRONE (eds.). 1996. Catálogo de las Plantas Vasculares de la República
Argentina, I. Pteridophyta, Gymnospermae y Angiospermae (Monocotyledoneae). Monographs in Systematic Botany, Volumen 60; Missouri Botanial Garden, St. Louis. Disponible en: http://www. darwin.edu.ar/Publicaciones/CatalogoVascII / CatalogoVascII.asp).

ZULOAGA, F. O. \& O. MORRONE (eds.). 1999. Catálogo de las Plantas Vasculares de la República Argentina, II. Angiospermae (Dicotyledoneae). Monographs in Systematic Botany, Volumen 74; Missouri Botanial Garden, St. Louis. Disponible en: http://www.darwin.edu.ar/Publicaciones/ CatalogoVascII /CatalogoVascII.asp).

ZULOAGA, F. O.; E. G. NICORA, Z. E. RÚGOLO DE AGRASAR, J. PENSIERO \& A. M. CIADILLA.1994. Catálogo de la Familia Poaceae en la República Argentina. Monographs in Systematic Botany, Volumen 47; Missouri Botanial Garden, St. Louis. Disponible en: http://www.darwin.edu.ar/ Publicaciones/CatalogoVascII /CatalogoVascII.asp

Recibido el 16 de octubre de 2015, aceptado el 18 de abril de 2016. 
